\title{
Positively Influencing Student Engagement and Attitude in Mathematics Through an Instructional Intervention Using Reform Mathematics Principles
}

\author{
Jeff Irvine ${ }^{1}$ \\ ${ }^{1}$ Brock University, St. Catharines, Ontario, Canada \\ Correspondence: Jeff Irvine, Brock University, St. Catharines, Ontario, Canada. E-mail: \\ jeffrey.irvine@brocku.ca
}

Received: December 30, 2019 Accepted: January 29, 2020 Online Published: February 5, 2020

doi:10.5539/jel.v9n2p48 URL: https://doi.org/10.5539/jel.v9n2p48

\begin{abstract}
Student engagement in their own learning of mathematics, and student attitudes towards mathematics are key dimensions of learning. This mixed methods study examined the impact of a classroom intervention based on the principles of reform mathematics (i.e., active student involvement, hands-on, real-world connections, use of manipulatives and technology, extensive use of student groups), on student engagement and student attitudes, in three Grade 10 mathematics classrooms in Ontario, Canada. Statistically significant effects were found for both the students' engagement and attitudes. The implications for pedagogy and policy indicated that the efficacy of reform mathematics principles influenced the students' affective dimensions in mathematics learning.
\end{abstract}

Keywords: engagement, attitude, reform mathematics, Ontario education policy

\section{Introduction}

Mathematical competency and its development are influenced by affective variables of the learners and characteristics of learning environments which may raise or support motivation. ...The awareness of affect and motivation as impact factors on learning has led to a multi-criteria perspective of instructional goals, with a simultaneous focus both on learning goals and goals of supporting motivation. (Kuntze \& Dreher, 2015, p. 296)

The purpose of this study was to investigate whether specific instructional strategies that explicitly address student motivation and metacognition can positively impact student engagement, attitude, and achievement in mathematics. The study utilized an instructional intervention with instructional strategies and activities that explicitly target student engagement and student attitude in order to positively influence resulting student outcomes.

\section{Background}

Attitude and engagement have a major impact on mathematics achievement and related educational goals (Conner \& Pope, 2013; Harlow, DeBacker, \& Crowson, 2011; Li \& Lerner, 2013; Ouweneel, Schaufeli, \& LeBlanc, 2013). Fredricks, Blumenfeld, and Paris (2004) found that a significant percentage of mathematics students lack motivation, have low mathematics self-efficacy, and generally exhibit low levels of engagement as well as negative attitudes towards mathematics. This situation is exacerbated by reliance on a transmission style of pedagogy, which encourages students to become passive content consumers rather than active participants during their learning (Cotic \& Zuljan, 2009; Moyer, Robison, \& Cai, 2018).

To date, globally there has been limited success in addressing the impact of attitude and motivation on student achievement (Clarkson, 2013). In Ontario, Canada, in a study that explicitly examined issues involving student motivation of over 90,000 students who wrote the Education Quality and Accountability Office (EQAO) Grade 9 Assessments in 2012, Pang and Rogers (2014) found large effect sizes for student attitudes and student self-confidence on achievement: Student attitude effect sizes ranged from 0.592 to 1.076; mean effect sizes for student confidence were 0.675 ; effect sizes for negative attitudes toward mathematics were also large, and ranged from -0.503 to -1.004 ; and effect sizes related to effort and engagement with homework ranged widely from 0.392 to 1.507. Effect sizes in these ranges have major impacts on student achievement. An effect size of +1.0 represents an increase for an average student performing at the 50th percentile to the 84 th percentile. 
Similarly, an effect size of -1.0 would move student performance from the 50th percentile to the 16 th percentile. Smith and Star (2007) claim that traditional methods that focus on content and ignore student emotions, attitudes, and motivation have performed very poorly. Therefore, it is imperative to identify ways to positively influence student attitudes toward and motivation to engage in mathematics.

This current study builds on research on components of motivation (i.e., engagement and attitude) in mathematics by examining whether instructional strategies specifically targeted at both metacognition and motivation positively impacted student attitude and engagement. Motivation is described as "an individual's desire to act in particular ways" (Walter \& Hart, 2009, p. 163); metacognition is "the knowledge about and regulation of one's cognitive activities in learning processes" (Veenman, Van Hout-Wolters, \& Afflerbach, 2006, p. 3). Both constructs have been shown to be important to student learning (Hannula, 2006; Koller, Baumert, \& Schnabel, 2001; Malmivuori, 2006; Veenman et al., 2006).

Many researchers treat motivation as a superordinate category that subsumes a few related concepts such as engagement, persistence, attitude, interest, self-efficacy, and self-concept (Irvine, 2018a). Since it is considered superordinate, motivation involves a wide array of theoretical constructs - such as expectancy-value or intrinsic-extrinsic - and many related theories, including self-efficacy, goal theory, theories of intelligence, choice theory, self-determination theory, and flow, among others (Irvine, 2018a). Because motivation involves such an array of constructs and theories, this current study focused on only two dimensions of motivation: engagement and attitude.

It should be noted that while most researchers accept the superordinate position of motivation, some (e.g., Singh, Granville, \& Dika, 2002) envision dimensions such as engagement and sometimes attitude as separate constructs and not within the motivation category. In addition, some researchers use motivation in a very narrow context. For example, in a widely used questionnaire on student attitudes, the motivation subscale of the Attitudes Towards Mathematics Inventory $\odot$ (Tapia \& Marsh, 2005) refers only to students being motivated to take additional mathematics courses and does not address any other aspects of motivation. However, as with most of the literature, this current study treated motivation as the superordinate category with both engagement and attitude as subordinates.

\section{Theoretical Framework}

The theoretical framework for development of the instructional intervention was Marzano's New Taxonomy of Educational Objectives $\odot$ (MNT; Marzano, 1998; Marzano \& Kendall, 2007). MNT comprises three domains or systems: self (including motivation), metacognitive, and cognitive. Marzano postulated that when confronted by a task, the self system (examining importance, efficacy, emotional response, and motivation) engages first, with decisions about whether to engage in the task. After deciding to engage in the task, the metacognitive system (specifying goals, process monitoring, monitoring clarity, monitoring accuracy) activates goal setting and monitoring. Finally, the cognitive system (retrieval, comprehension, analysis, knowledge utilization) engages in the actual cognitive work of the task. MNT has implied but not explicit feedback loops, with metacognitive goal monitoring and process monitoring, and self system monitoring comparing current task engagement to other alternatives.

Figure 1 identifies the subsystems of MNT and the two systems (self and metacognitive) that were the focus of this study. The instructional intervention was developed in conjunction with the teachers and utilized the self and the metacognitive systems as a foundation on which to build classroom activities and a unit plan (the "MNT intervention") that focused on these two systems to increase student engagement and positively modify student attitudes towards mathematics. 


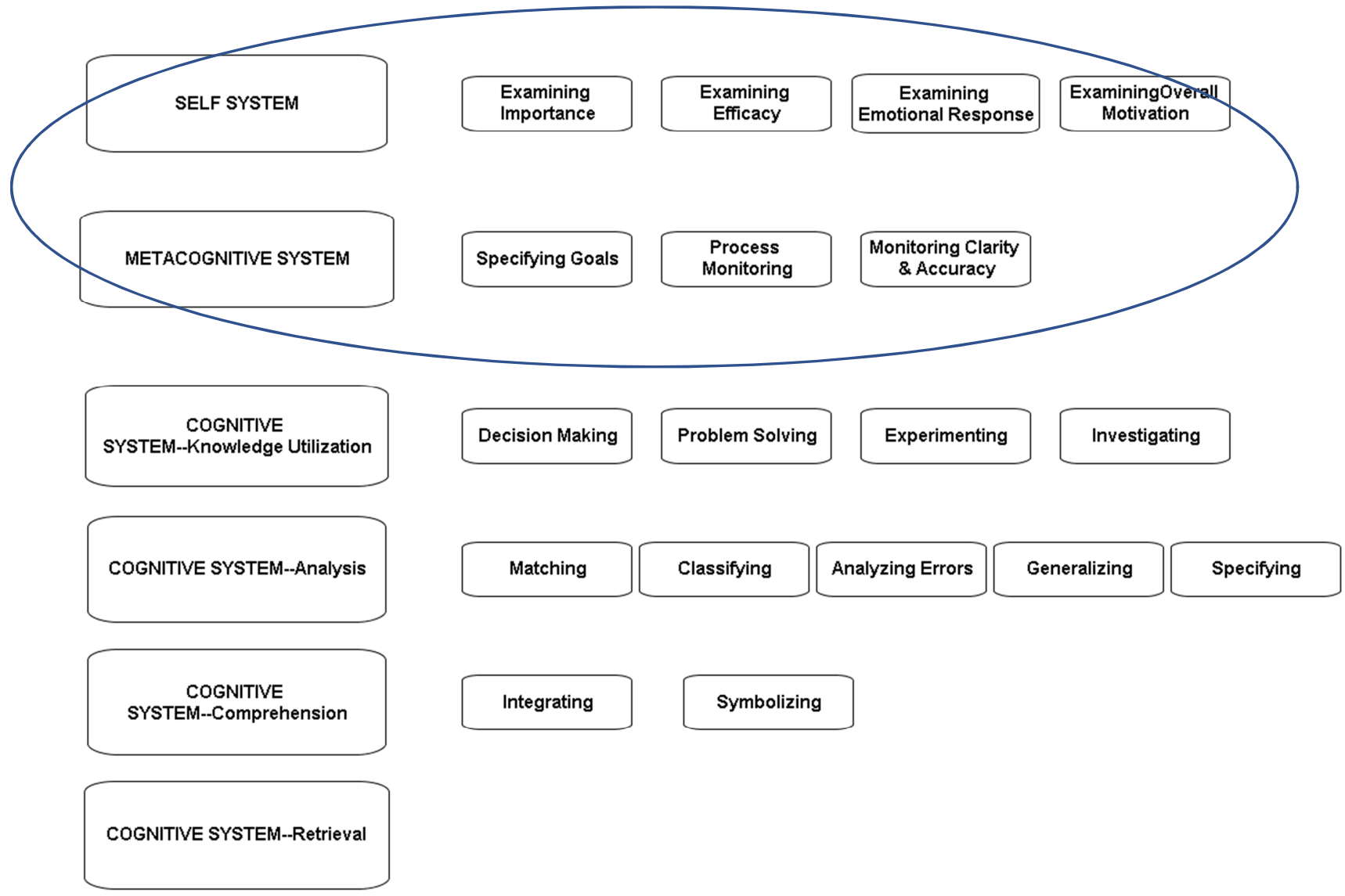

Figure 1. Affective dimensions addressed in Marzano's New Taxonomy self and metacognitive systems

\section{Research Questions}

1) What is the effect of the MNT intervention on student engagement in a Grade 10 Academic Mathematics classroom(s)?

2) What is the effect of the MNT intervention on student attitudes in a Grade 10 Academic Mathematics classroom(s)?

3) What are the pedagogical and policy implications of this study?

\section{Review of the Literature}

This section outlines research on the variables of interest in this study: student engagement and student attitudes towards mathematics.

\subsection{Engagement}

The first dependent variable in this study was engagement. Engagement has been described as "a positive and inspiring state of mind that is characterized by vigor, dedication, and absorption" (Ouweneel et al., 2013, p. 225). Reeve (2013) emphasizes the proactive nature of engagement, stating that "Engagement refers to a student's active involvement in a learning activity. It functions as a student-initiated pathway to highly valued educational outcomes, such as academic progress and achievement" (p. 579). Engagement is identified as "one of the most important issues facing educators today" (Conner, 2011, p. 53).

The literature usually identifies three components of engagement: behavioural, emotional or affective, and cognitive (Ouweneel et al., 2013). Behavioural engagement includes basic behaviours such as attending class, following the rules, demonstrating effort, persistence, asking questions, paying attention, positive classroom behaviours, and making an effort (Fredricks et al., 2004). It is the most potentially observable component and has been the most studied (Conner \& Pope, 2013). Emotional engagement consists of affective-usually classroom - demonstrations of emotion, such as interest, boredom, happiness, sadness, and anxiety (Fredricks et al., 2004). There are a number of components of cognitive engagement identified in the literature. These include preference for hard work, flexible problem solving, self-regulation, the use of metacognitive strategies, and 
coping with failure (Conner \& Pope, 2013). Several scholars have restricted cognitive engagement to deep versus surface learning (Paige, Sizemore, \& Neace, 2013; Smiley \& Anderson, 2011).

Many of these concepts overlap with dimensions of motivation and higher-order thinking skills. Most of the definitions of engagement also suffer from identifying the behaviours associated with components of engagement, rather than the underlying constructs.

Reeve and Lee (2013) have argued for a fourth component to engagement, which they call agentic engagement. Reeve (2013) defines agentic engagement as "students' constructive contribution into the flow of the instruction they receive" (p. 579). Agentic engagement is characterized by student self-advocacy, such as asking questions, offering opinions and identifying areas of student interest, and stating preferences (Reeve \& Lee, 2013). Agentic engagement can be identified through the level of response to five statements:

- During class, I ask questions.

- I tell my teacher what I like and what I don't like.

- I let my teacher know what I'm interested in.

- During class, I express my preferences and opinions.

- I offer suggestions about how to make the class better. (Reeve \& Lee, 2013, p. 580)

These questions characterize the proactive nature of agentic engagement; that is, students seek to modify the learning environment to enhance and maximize their own learning. Agentic engagement somewhat overlaps concepts from both emotional engagement and cognitive engagement; however, what is qualitatively different is the emphasis on self-advocacy. Reeve and Lee (2013) conducted a study in which principal factor analysis identified all four components of engagement, including agentic engagement, as separate constructs that are each correlated with student achievement.

There is some debate concerning whether engagement is a trait, possibly domain, variable, relatively stable over time; or a state variable, task dependent, and malleable (Vera, Le Blanc, Taris, \& Salanova, 2014). Fredricks et al. (2004) point out that this may vary by engagement situation. For example, for the school domain, behavioural engagement may be high and stable; however, for some subject domains, emotional engagement may be high (or low), and cognitive engagement is likely to vary based on task.

Lilejdahl (2014) identifies engagement with Csikszentmihalyi's concept of flow. While the concept of flow is outside the scope of this study, it is informative to examine the logic behind Lilejdahl's position. He conceptualizes flow (and thus engagement) as the tension between skill and challenge. If the task requires challenge exceeding the student's skill level, the result is anxiety. If skill exceeds challenge, the result is boredom. However, if there is a balance between skill and challenge, the student is engaged and will tend to exhibit observable indicators of all three components of engagement described above. The relationship between engagement and flow is also identified by Fredricks et al. (2004) as being related to emotional engagement. Lilejdahl's characterization appears more compelling, because flow exhibits dimensions of behavioural and cognitive engagement as well as emotional engagement. However, achieving flow is an extremely high standard for identifying student engagement. Clearly, students can be engaged without reaching a state of flow.

A few scholars have related work on engagement to other theories, usually involving constructs from motivation. These include relating engagement to self-determination theory (Fredricks et al., 2004; Reeve, 2013), social cognitive theory (Smart \& Marshall, 2013), self-regulation (Reeve, 2013), and emotional response theory (Mazer, 2013).

Reeve and Lee (2013) postulate a reciprocal symbiotic relationship between motivation and engagement. They theorize that positive changes in motivation will result in positive changes in engagement. These changes in engagement will lead to more positive changes in motivation, which in turn will lead to more changes in engagement, in a reciprocal manner.

Superficially, engagement appears to be a relatively well understood construct, with general agreement on three (possibly four) major components. Fredricks et al. (2004) argue that the relationships among the components are dynamic and engagement is malleable. This is complicated by the place of engagement in the motivational literature, sometimes seen as a subcomponent of motivation and sometimes treated as a separate construct. Engagement is recognized in some studies as an important factor in student achievement, with the role of the teacher being critical in enhancing student engagement at all levels of schooling (Dotterer \& Lowe, 2011). Patrick, Ryan, and Kaplan (2007) point out that engagement is a mediator of student beliefs, as are peer influences and teacher influences; that engagement is responsive to the classroom social environment; and that 
these relationships are reciprocal in that levels of student engagement also influence classroom social environments, peer behaviours, and teacher behaviours. Zyngier (2007) echoes this conception of engagement and claims an important link between engagement and student attitudes.

\subsection{Measuring Engagement}

Ouweneel et al.'s (2013) description of engagement cited at the outset of this section demonstrates some of the difficulties with the construct of engagement. First, it is a latent variable and is unobservable directly. The usual methods for measuring engagement are self-report surveys and observation (Mazer, 2013; Plenty \& Heubeck, 2013). Both of these methods have limitations. Self-report surveys are frequently upwardly biased (Hattie \& Yates, 2014) and may lack reliability. Self-report surveys may also suffer from social desirability bias (Caskie, Sutton, \& Eckhardt, 2014) as well as non-response bias (Mundia, 2011) and other forms of bias that could influence the accuracy of the results. Engagement may also be assessed using interviews, which may be more frequently affected by social desirability bias due to the limited anonymity of the respondent (Desimone, Smith, \& Frisvold, 2010). Engagement is a difficult to observe construct, and thus it must be imputed from overt behaviours and therefore can be difficult to interpret.

Second, the three traditionally recognized components of engagement (behavioural, emotional, cognitive) are not always independent. Fredricks et al. (2004) point out that there are overlapping constructs among these, and that engagement must be viewed as a dynamic interrelationship of the three components. Third, as can be seen from the above discussion on agentic engagement, there is not universal agreement on identifying the components or even how many components of engagement are valid. Finally, there is considerable overlap with other concepts from motivation (Archambault, Janosz, Morizot, \& Pagani, 2009). A significant advantage of agentic engagement, as defined by Reeve (2013), is that it can be identified through student responses to the five statements outlined above. While still a self-report, the questions are more factual in nature and thus may have higher reliability.

Fredricks et al.'s (2004) literature review examined engagement measurement concepts and tools across a number of studies. They report that most measurement instruments comingled scales and questions across multiple components of engagement. Further, the actual questions related to each component varied dramatically. Behavioural measures included questions on conduct, persistence, effort, attention, participation, and helpless behaviours. Emotional engagement questions included student-teacher relations, feelings, values, work orientation and persistence, and school orientation and persistence. Cognitive questions listed psychological investment in learning, flexible problem solving, preference for hard work, independent work styles, ways of coping with perceived failure, preference for challenge, and several questions related to intrinsic motivation (Fredricks et al., 2004). Fredricks et al. point out that many of the studies used questions that overlap across two or more of the engagement components. They found that the majority of studies involved behavioural engagement since it is perceived to be the easiest component to observe.

The instrument used in this study was the Dimensions of Student Engagement Survey(C) (DSES; Reeve, 2013) which addresses engagement and disengagement across all four subscales of engagement, namely behavioural, cognitive, emotional, and agentic. The DSES is a 39-item Likert scale survey, that has been validated as a good measure of engagement (Reeve \& Lee, 2013).

\subsection{Engagement in Mathematics Classes}

There are limited studies of engagement that are domain specific. Often in these studies, engagement is measured as a component of, or alongside, motivation. For example, Plenty and Heubeck (2013) studied changes in overall motivation among students as they progressed through their high school years; they found that motivation in mathematics is lower than it is in school, in general, and lower than for some other subjects, and that this relationship is relatively stable over time. However, they also found that valuing of mathematics and student self-efficacy in mathematics (possibly related to emotional engagement) increased in the later years of high school compared to the early years. The study reported motivation as the metavariable, with engagement as a subvariable.

Shernoff, Csikszentmihalyi, Schneider, and Shernoff (2003) found very low levels of engagement in mathematics classes, where they reported that the classes had very high cognitive intensity but very low motivation. Students reported being more negative about mathematics and less engaged than any other subject. While studies report correlations between engagement and achievement in mathematics (e.g., Bodovski \& Farkas, 2007; Moller, Stearns, Mickelson, Bottia, \& Banerjee, 2014), engagement is also recognized as an important outcome variable in its own right (Collie \& Martin, 2017). Engagement has been positively linked to perceptions of mathematics (Fung, Tan, \& Chen, 2018); attitudes towards mathematics (Bodovski \& Farkas, 
2007); student agency in mathematics (Collie \& Martin, 2017); and student graduation rates as well as students pursuing higher education (Bodovski \& Farkas, 2007).

\subsection{Teacher Behaviours Support Student Engagement}

Classroom environment and teacher behaviours play a large role in student motivation and engagement. Conner and Pope (2013) note that student engagement declines over the course of a student's time in school, and that "by upper high school, $40 \%$ to $60 \%$ of students are disengaged" (p. 1427). Schussler (2009) identified the critical role that teachers play in maintaining and increasing student engagement, through what she calls "a synergy of care and high expectations" (p. 116). Archambault, Janosz, and Chouinard's (2012) study emphasized a similar stance in mathematics classrooms. They point out that mathematics teachers are frequently criticized for failing to engage student interest and motivation. They challenge mathematics teachers to engage in behaviours that increase student motivation, engagement, and attitudes. Archambault et al. (2012) emphasize that such teacher behaviours will require significant changes in teacher beliefs about the learning of mathematics, which may be problematic.

Teacher practices must be intentional with respect to student engagement (Skilling et al., 2016). Instructional strategies play a large role in student engagement. Strategies that are active, involve students working in groups, employ problem-based learning, and ask students to explain their thinking (collectively referred to as reform mathematics curricula) were found by Moyer et al. (2018) to have long-lasting effects on student engagement. In a survey of Kindergarten to Grade 12, Smith and Star (2007) found that instruction that involved manipulatives, hands-on activities, real-world problems, and student groups had positive impacts on engagement across all grade levels studied.

Another important instructional strategy that encourages engagement is student choice (Irvine, 2018b). Student choice responds to students' need for autonomy, one of the three core needs identified in self-determination theory, together with needs for competence and relatedness (Deci \& Ryan, 2008). By providing students with some level of choice in some activities, such as a choice of solution methods, choice of problems to be addressed, or a choice of product to demonstrate their learning, teachers support student autonomy, which has been found to foster increased engagement (Deci, Vallerand, Pelletier, \& Ryan, 1991). Conversely, teacher-directed learning was found to have a significant negative effect on engagement and an increase in students' use of avoidance strategies in mathematics classes (Turner et al., 2002).

The instructional intervention designed for the classroom intervention in this study was based on the research-affirmed principles discussed above. Specific instructional strategies chosen from Table 1 recognized the need for intentionally addressing both student engagement and student attitudes through providing choice, manipulatives, hands-on activities, real-world connections, and student social needs through the use of student groups.

Table 1. Instructional strategies by Domain

\begin{tabular}{lll}
\hline Self & Metacognitive & Cognitive \\
\hline Explicit questions: interest, importance, & Explicit questions: goal setting, process & Explicit questions: similarities and differences, \\
efficacy & monitoring, monitoring clarity \& accuracy & open questions \\
Open questions & Open questions & Open questions \\
Student choice & Web and decision trees & Jigsaw \\
PMI & PMI & RAFT \\
Journals & Journals & Journals \\
Post it pileup & Anticipation guides & Inside/outside circle \\
Placemat & Placemat & Placemat \\
What/so what double entry & What/so what double entry & What/so what double entry \\
Graffiti & Graffiti & Graffiti \\
Four corners & Four corners & Timed retell \\
RAFT & Timed retell & Ticket to leave \\
Ticket to leave & Ticket to leave & Problem posing \\
Graphic organizers & Think aloud & Graphic organizers \\
Connect to real-life applications & Graphic organizers & Problem posing \\
Choice on assessments & & \\
Crossword puzzles & & \\
\hline
\end{tabular}




\subsection{Attitude}

The second dependent variable in this study was student attitudes. Researchers' comments concerning the importance of attitude include: "a critical construct related to learning" (Vandecandelaere, Seabrook, Velar, Frayne, \& Van Damme, 2012, p. 107); "one of the most key factors that relates to achievement" (Mohd \& Mahmood, 2011, p. 1857); and "most researchers have verified the link between students' attitude and their performance in mathematics" (Maat, Zakaria, Nordine, \& Embe, 2010, p. 201). However, similar to studies of engagement, this position relating attitudes to achievement is not unanimous (e.g., Di Martino \& Zan, 2009; Hannula, 2006).

Vandecandelaere et al. (2012) present a number of definitions of attitude, both as a general attribute of learners and also as particularly related to mathematics. Among these are: an evaluative disposition towards some object based upon cognition, affective reaction, behavioural intentions, and past behaviour that can influence cognitions, affective responses, and future intentions and behaviours.

Several studies list beliefs, emotional response, and behaviour as components of attitude (e.g., Yaratan \& Kasapoglu, 2012). These attitude dimensions differ from engagement, however, in that they are a priori states, prior to engaging in the task, as compared to similar constructs in engagement, which apply during the task.

Sometimes, researchers choose to define attitude using only one dimension. For example, in his seminal work on beliefs, attitudes, and emotions, McLeod (1992) defined attitude as "a long-term positive or negative emotional disposition towards mathematics" (p. 787). While this has the advantage of brevity, and it does emphasize that attitude is a long-term disposition, the definition lacks the fullness that is obtained by inclusion of other dimensions beyond the emotional. As can be seen from the above, attitude appears to consist of several constructs chosen from among self-confidence, interest, emotional response, behavioural intentions, value, beliefs, and expected outcomes. Some authors also identify motivation as a dimension of attitude. This is problematic, as motivation is usually considered a superordinate concept and attitude a subordinate concept (Irvine, 2018a). Marzano and Kendall (2007) identify motivation as the superordinate construct with subordinate constructs consisting of importance, self-efficacy, and interest.

\subsubsection{Attitudes Towards Mathematics}

Factors influencing attitudes of students toward mathematics are complex (Mata, Monteiro, \& Peixoto, 2012). Ediger (2012), in discussing quality teaching of mathematics, lists six statements about attitudes that are illuminating: attitudes are evaluative and can be presented on some continuum of favourableness; attitudes vary in intensity and direction; some attitudes are accompanied by or connected with a person's emotions; attitudes are relatively durable; attitudes are learned and can therefore be taught; and attitudes are related to behaviour. Three of these statements directly influenced this study: attitudes are related to emotions, they are durable, and they can be taught.

Vandecandelaere et al. (2012) state that when analyzing the items on mathematics attitude in the Trends in Mathematics and Science Study (TIMSS) 2003, three dimensions of mathematics attitude were identified: self-confidence, liking mathematics, and usefulness of mathematics. These three dimensions are very similar to a model proposed by Di Martino and Zan (2009) based on qualitative analysis of essay responses of 1,496 Italian students from Grades 2 through 13 to the topic "Me and maths." Analysis produced three dimensions: perceived competence, emotions towards mathematics, and vision of mathematics.

It is also insightful to examine the origins of students' mathematical attitudes. Hannula (2002) developed a four-phase model of attitude towards mathematics. This model proposes that students evaluate a mathematics task in four sequential phases. First is an emotional response to the task; this is typically a quick response based only on emotion at the moment. The second phase is an associative evaluation, based on similarities to tasks that the student has encountered in the past. The third phase is a competency evaluation, where the student decides whether he or she feels competent to attempt the task. The fourth phase is evaluation based on the student's personal goals, both short term and longer term. Each evaluative phase may return positive or negative results, influencing the student's final decision regarding how to engage with the task. This is similar to Marzano's self system.

Lim and Chapman (2013) identify four dimensions of attitude as enjoyment, motivation, self-confidence, and value. The instrument used in this study, Attitudes Towards Mathematics Inventory $\mathbb{C}$ (ATMI; Tapia \& Marsh, 2005) contains the same four subscales. The ATMI is a widely used instrument that has substantial validation in the literature (Majeed, Darmawan, \& Lynch, 2013).

Various researchers have identified sources of attitude as parents, teachers, teaching methods, peer groups, 
self-confidence, previous experiences, motivation, and teachers' evaluations (Yaratan \& Kasapoglu, 2012). Of note is the reciprocal nature of some of these, especially self-confidence, previous experiences, and motivation. In Ontario, a recent EQAO (2014) analysis emphasized this reciprocity when it identified students who had previously been unsuccessful on EQAO assessments as having negative attitudes towards mathematics, as well as lower self-confidence and lower overall motivation. These negative attitudes were reflected in lower achievement on the current EQAO assessment.

An extreme dimension of mathematics attitude is math anxiety. Math anxiety includes worry and fear, dislike, frustration, distress, tension, helplessness, and mental disorganization (Yaratan \& Kasapoglu, 2012). While math anxiety is outside the scope of this current study, the impact on student achievement of this extreme attitude toward mathematics is noteworthy. In a synthesis of over 800 meta analyses of factors impacting student achievement, Hattie (2009) cites an effect size of math anxiety of -0.34 on mathematics achievement. Thus, a student who was performing at the 50th percentile in mathematics would, due to math anxiety, perform below the 38th percentile.

\subsubsection{Teacher Behaviours That Support Positive Student Attitudes in Mathematics}

As with engagement, teachers have a major impact on student attitudes. Because attitudes are formed both directly and indirectly through reactions to situations or the environment, they are, therefore, malleable (Vandecandelaere et al., 2012). Measures can be adopted to influence attitudes in a positive direction. Ediger (2012) points out that the teacher serves as a role model for students. If the teacher's attitude reflects interest, enthusiasm, and enjoyment, it is more likely that these attitudes will influence students' attitudes in similar directions (Smith \& Star, 2007). Teacher attitudes have a significant effect on both student attitudes and student achievement. Hattie (2009) identified an effect size on student achievement of 1.04 for teacher attitudes with respect to influencing student achievement. Thus, teacher attitudes can change student achievement for the average student by more than 34 percentile points. In a more general study of student beliefs and goal orientation, Mesa (2012) found that students' beliefs were significantly affected by teacher behaviours. The instructional intervention in the current study was of a relatively short length (approximately 4 weeks), which McLeod (1992) would predict to have limited impact on student attitudes. However, if changes in attitude do occur, they should have a relatively longer-lived duration.

Modifications to the learning environment, including teaching strategies, can also have a powerful effect on student attitudes (Vandecandelaere et al., 2012). Domino (2009) identified three dimensions of teacher behaviours that influenced student attitudes toward mathematics: instructional strategies, ensuring student understanding, and teacher care. Instructional strategies similar to those identified for encouraging student engagement also have positive influences on student attitudes (Elçi, 2017). Other factors influencing attitude towards mathematics include perceived teacher care (Cooper \& Miness, 2014); teacher's displays of enjoyment (Frenzel, Goetz, Ludke, Pekrun, \& Sutton, 2009); teacher fairness (Mata et al., 2012); classroom climate, especially social climate (Kunter et al., 2008). Ironically, teacher care may also result in social desirability bias when students who perceive their teacher as caring complete questionnaires or interviews about classroom activities (Krupa, 2017). OECD (2016a, 2016b) reported that high levels of teacher-directed activities had negative impacts on student attitudes in mathematics while a mix of direct instruction and student activities had positive impacts on attitudes. As with engagement, these teacher behaviours that support positive student attitudes towards mathematics were central to the design of the instructional intervention used in this study.

\subsubsection{Student Attitudes and Mathematics Achievement}

A number of correlational studies have identified significant correlations between attitude and mathematical achievement (e.g., Marchis, 2011; Yaratan \& Kasapoglu, 2012). However, this correlation has not been universally supported by research, which in some cases found very weak correlations or no correlations at all (e.g., Di Martino \& Zan, 2009; Hannula, 2002). Vandecandelaere et al. (2012) state that "attitude towards mathematics is a vital matter in mathematics education" (p. 107). This consensus is all the more surprising considering that the definitions of attitude are very diverse.

All of these dimensions with respect to attitude require teachers of mathematics to have sufficient content knowledge for teaching mathematics (Ball \& Bass, 2003). Ediger (2012) lists considerations around pedagogical content knowledge; necessary knowledge includes: what ideas about or understanding of a concept students are likely to have before instruction; typical difficulties students tend to have in learning a given concept or topic; what order to introduce concepts and skills to minimize confusion about a topic; what strategies work to help different kinds of students overcome common difficulties; how to choose and use instructional materials; what models/analogies/visualizations/activities work well to convey specific understandings; and how to assess what 
students have learned about a given topic.

\subsubsection{Motivation and Achievement in Mathematics}

A significant body of evidence shows that motivation in mathematics (or one or more of the dimensions of motivation) has a major role in mathematics achievement (Hannula, 2006; Koller et al., 2001; Malmivuori, 2006) In addition, there is a demonstrated reciprocal symbiotic relationship between motivation and achievement (Koller et al., 2001; Middleton \& Spanias, 1999). Further, a Toronto Star article reporting on the practice of streaming students in secondary schools stated, "The problem is that student achievement often has more to do with motivation than innate intelligence" (Maharaj, 2014, para. 1). Thus, low achievement leads to low motivation and low motivation leads to low achievement in a debilitating spiral.

These findings emphasize the important role that teachers play in addressing students' motivation, and breaking the prioritization that Middleton (1995) identified as content goals taking precedence over student motivational considerations in mathematics instruction:

If mathematics is intrinsically motivating to some students but not to others, it seems reasonable to assume, then, that individual differences among students, and the ways in which mathematics education complements these differences, determine to a large extent the degree to which mathematics is perceived as motivating. (p. 255)

Middeleton and Spanias (1999) found that motivation in mathematics develops early, is highly stable, but is greatly influenced by teacher actions and attitudes. Therefore, motivation in mathematics can be affected through careful instructional designs. For example, Cotic and Zuljan (2009) found that mathematics activities involving problem solving and problem posing had a significant positive impact on cognition and affect, and thus on motivation. Since motivation has been linked to mathematics achievement, teacher actions and attitudes are an important consideration in enhancing student achievement. This current study focuses on two dimensions of motivation, engagement and attitude. While self-efficacy has been shown to have a large impact on achievement, self-efficacy is very resilient and difficult to change, especially in the short term. Since this current study was limited to approximately four weeks duration, the probability of modifying self-efficacy is low, while engagement is malleable in the short term, and attitude can be modified in the intermediate term. Thus, engagement and attitude are the constructs of motivation that served as dependent variables in this study, as well as student achievement.

DeBellis and Golding (2006), expanding on the seminal work by McLeod (1992), identified a taxonomy of affect, consisting of four constructs: emotions, which are rapidly changing states of feeling, mild to very intense, usually local or embedded in context; attitudes, moderately stable predispositions toward ways of feeling in classes of situations, involving a balance of affect and cognition; beliefs, internal representations to which the believer attributes truth, validity, or applicability, usually stable and highly cognitive, sometimes highly structured; values, ethics, and morals, deeply held preferences, stable, highly affective as well as cognitive, may also be highly structured, sometimes characterized as "personal truth." In the current study, engagement falls in the emotions' category, while attitude, characterized as "moderately stable," is considered somewhat malleable.

In the research literature, engagement is frequently identified as a mediator variable with respect to achievement (e.g., Koller et al., 2001), while attitude is often cited as a moderator variable with respect to achievement (e.g., Middleton, 1995).

\section{Methodology and Methods}

Engagement and attitude are latent variables (Reeve, 2013; Vandecandelaere et al., 2012). Most dimensions of engagement and attitude cannot be observed directly but rather must be inferred from observations or student responses to surveys or interview questions; this makes measuring changes in engagement and attitude problematic. In order to make warranted assertions about these latent variables, multiple data sources are needed to provide sufficient evidence; therefore, a mixed methods methodology (Teddlie \& Tashakkori, 2009) was employed.

Mixed methods methodology is defined as "the class of research where the researcher mixes or combines quantitative and qualitative research techniques, methods, approaches, concepts or language into a single study" (Johnson \& Onwuegbuzie, 2004, p. 17). This study employed both quantitative and qualitative methodologies to investigate the impact of the MNT intervention on student engagement and student attitudes.

\section{Selection of Site and Participants}

Grade 10 Academic Mathematics (MPM2D; Ontario Ministry of Education, 2005) was identified as the course 
to be used for this research. By selecting this subject and level, the classes tend to be more homogeneous in background, thus reducing the impact of confounding variables not involved in the study. For example, since usually all students in MPM2D have attained a credit in Grade 9 Academic Mathematics, their background knowledge is somewhat more homogeneous. Socio-economic variables are usually dependent on school location. All classes in this study were selected from the same secondary school, located in Ontario, Canada. The school selected for this study had a student population of 1,914, with five sections of Grade 10 Academic Mathematics occurring in Semester 2 of the 2017-2018 school year. Two teachers volunteered to participate. Both held Mathematics Specialist's certificates and had considerable teaching experience (10 years and 22 years). One teacher had two sections of the course which were designated as the treatment classes (T1 and T2). The second teacher had one class, which was designated as the control class. A total of 68 students participated in the study. The combined treatment classes were $60 \%$ female.

\section{Instrumentation}

All quantitative student surveys regarding student engagement and student attitude were conducted using computer software (SurveyMonkey ${ }^{\mathrm{TM}}$ ). Since the research was conducted in a bring your own device (BYOD) school district, this use of technology was both appropriate and potentially engaging to students.

\subsection{Engagement}

Engagement was assessed with pre- and post student surveys, student reflections and interviews, and teacher interviews. To measure student engagement quantitatively, pre- and post surveys using Reeve's (2013)

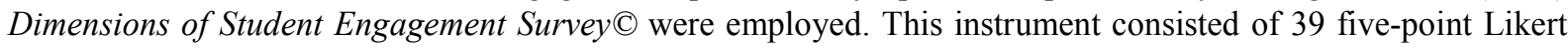
scale questions ( $1=$ Strongly Disagree to $5=$ Strongly Agree). This survey had four subscales: behavioural engagement, emotional engagement, cognitive engagement, and agentic engagement. The DSES had an excellent Cronbach's $\alpha$ of 0.95 on 39 items. All four subscales (cognitive engagement, behavioral engagement, emotional engagement, and agentic engagement) had strong Cronbach's $\alpha$ values as well (Table 2). This is consistent with reliability values found in the literature (Reeve, 2013).

Table 2. Reliability for Dimensions of Student Engagement Survey and subscales

\begin{tabular}{lll}
\hline Scale & Number of items & Cronbach's $\alpha$ \\
\hline Engagement (full scale) & 39 & 0.950 \\
Cognitive & 12 & 0.855 \\
Behavioral & 10 & 0.853 \\
Emotional & 7 & 0.898 \\
Agentic & 10 & 0.867 \\
\hline
\end{tabular}

Qualitative data consisted of interviews with five student volunteers after the completion of the intervention; preand post-intervention interviews with the two teachers; student weekly reflections; researcher observations of approximately $25 \%$ of the classes during the intervention.

\subsection{Attitude}

To measure student attitudes quantitatively, the Attitudes Towards Mathematics Inventory $₫$ (ATMI; Tapia \& Marsh, 2005) was used. This survey used a five-point Likert scale ( $1=$ Strongly Disagree to $5=$ Strongly Agree). The $A T M I$ was a 40-item questionnaire, with four subscales: value, self confidence, enjoyment, and motivation. It should be noted that the motivation subscale refers to student motivation to take additional mathematics courses. The ATMI had an excellent Cronbach's $\alpha$ of 0.978. This is consistent with results in the literature (Asante, 2012). All four subscales, value, self confidence, enjoyment, and motivation had strong Cronbach's $\alpha$ values as well (Table 3); these values were consistent with values found in the literature (Majeed et al., 2013).

The qualitative measurement of attitudes utilized student and teacher interviews, as outlined above for engagement. Therefore, for both engagement and attitude, multiple data sources were developed.

Table 3. Reliability of Attitudes Towards Mathematics Inventory and subscales

\begin{tabular}{lll}
\hline Scale & Number of items & Cronbach's $\alpha$ \\
\hline Attitudes (full scale) & 40 & 0.978 \\
Value & 10 & 0.938 \\
Self confidence & 11 & 0.927 \\
Enjoyment & 14 & 0.962 \\
Motivation & 5 & 0.910 \\
\hline
\end{tabular}




\section{Instructional Intervention}

MNT was used as the theoretical framework to develop the instructional intervention. Since cognition is involved in all learning, the MNT intervention focused on the self system and the metacognitive system (Figure 1). Each activity was explicitly linked to an MNT sublevel, as shown in the example in Table 4. While each activity was linked to a sublevel of the self or metacognitive systems, the effectiveness of this instructional intervention was evaluated on a holistic basis without attempting to disentangle individual effects for each sublevel. The instructional intervention was designed by the researcher, based on instructional strategies outlined in Table 1 and explained in detail to the teachers involved prior to deployment in the classrooms. The instructional intervention took an active stance based on the principles of reform mathematics, using activities involving manipulatives, groups, and real-world problems. Technology was viewed as appropriate, since this was a BYOD school. The intervention consisted of a mixture of entire lessons activities interwoven with direct instruction; and short student surveys and goal-setting activities.

Control classes received lessons on the same topics of study, but without a focus on the metacognitive and self domains of MNT. In this way, effects of the intervention on student engagement and student attitudes could be isolated from general classroom effects based on mathematics content and teacher instructional practices. This study was approved by the university Research Ethics Board (file \#17-096).

Table 4. Linking of activities to MNT sublevels of self and metacognitive systems

\begin{tabular}{|c|c|c|c|c|c|}
\hline Expectations & Learning Goals & & & $\begin{array}{l}\text { Metacognition } \\
\text { Focus }\end{array}$ & Self Focus \\
\hline $\begin{array}{l}\text { - determine, through } \\
\text { investigation with } \\
\text { and without the use of } \\
\text { technology, that a } \\
\text { quadratic relation of the form } \\
y=a x^{2}+b x+c(a>0) \text { can be } \\
\text { graphically } \\
\text { represented as a parabola, and } \\
\text { that the table } \\
\text { of values yields a constant second } \\
\text { difference } \\
\text { (Sample problem: Graph the } \\
\text { relation } \\
y=x^{2}-4 x \text { by developing a table } \\
\text { of } \\
\text { values and plotting points. }\end{array}$ & $\begin{array}{l}\text { *Students will learn } \\
\text { the basic properties of } \\
\text { parabolas and be able } \\
\text { to describe these } \\
\text { properties using } \\
\text { appropriate } \\
\text { mathematical language } \\
\text { *Students will learn } \\
\text { how to apply quadratic } \\
\text { regressions to data sets } \\
\text { *Students will learn } \\
\text { how to use finite } \\
\text { differences to } \\
\text { determine equations of } \\
\text { quadratic functions }\end{array}$ & Minds On & $\begin{array}{l}\text { Carousel } \\
\text { - crocodile river } \\
\text { - handshake problem } \\
\text { - pizza cuts } \\
\text { - logpile } \\
\text { - paper folding }\end{array}$ & $\begin{array}{l}\text { - Anticipation } \\
\text { Guide }\end{array}$ & $\begin{array}{l}\text { - Likert scale: interest } \\
\text { - Groups } \\
\text { - Placemat: Tell me } \\
\text { everything you know } \\
\text { about linear relations }\end{array}$ \\
\hline $\begin{array}{l}\text { Observe the } \\
\text { shape of the graph. Calculate first } \\
\text { and } \\
\text { second differences. Repeat for } \\
\text { different } \\
\text { quadratic relations. Describe your } \\
\text { observations } \\
\text { and make conclusions, using the } \\
\text { appropriate terminology.); }\end{array}$ & & Action & $\begin{array}{l}\text { Whole class } \\
\text { - Use the method of } \\
\text { finite differences to } \\
\text { find equations for each } \\
\text { pattern } \\
y=a x+b \text { (linear) } \\
y=a x^{2}+b x+c \\
\text { (quadratic) }\end{array}$ & $\begin{array}{l}\text { - Think Aloud } \\
\text { - What do we } \\
\text { want to know; } \\
\text { what do we } \\
\text { know; how can } \\
\text { we connect } \\
\text { these }\end{array}$ & $\begin{array}{l}\text { - Likert scale: } \\
\text { importance }\end{array}$ \\
\hline $\begin{array}{l}\text { - identify the key features of a } \\
\text { graph of a } \\
\text { parabola (i.e., the equation of the } \\
\text { axis of } \\
\text { symmetry, the coordinates of the } \\
\text { vertex, } \\
\text { the } y \text {-intercept, the zeros, and the } \\
\text { maximum } \\
\text { or minimum value), and use the } \\
\text { appropriate terminology to } \\
\text { describe them; }\end{array}$ & & $\begin{array}{l}\text { Consolidate/ } \\
\text { Debrief } \\
\text { Homework: } \\
\text { Parabolas in } \\
\text { Real Life }\end{array}$ & $\begin{array}{l}\text { - Extend the pattern to } \\
\text { negative x's using your } \\
\text { equations } \\
\text { - Terminology (vertex, } \\
\text { max/min, axis of } \\
\text { symmetry, intercepts, } \\
\text { domain, range) }\end{array}$ & $\begin{array}{l}\text { - Journal entry } \\
\text { - How well was } \\
\text { your plan } \\
\text { achieved? Did it } \\
\text { require any } \\
\text { modifications? }\end{array}$ & $\begin{array}{l}\text { - (R) Connecting } \\
\text { Cube Quadratics } \\
\text { - Homework } \\
\text { Crossword puzzle } \\
\text { terminology }+ \\
\text { Parabolas in Real Life }\end{array}$ \\
\hline
\end{tabular}




\section{Classroom Procedures}

The teachers taught the first week of the unit. At the end of each week, students completed a brief reflection. Throughout the study, teachers completed brief daily reflections. Teachers then delivered the next weeks of the lessons and students completed reflections at the end of each week. Two written summative assessments occurred; one assessment occurred part way through the unit and the other a final summative assessment. At the end of the unit, students completed a rich assessment task, and again completed surveys on engagement and attitude.

\section{Selected Results}

This section identifies key results from this study with respect to engagement and student attitudes.

\subsection{Engagement}

Engagement was the first dependent variable to be examined. Both quantitative and qualitative data were collected and analyzed.

\subsection{Quantitative Findings}

All students completed pre- and post surveys of engagement using the Dimensions of Student Engagement SurveyC (DSES).

\subsubsection{Pre-Post Comparisons}

Scores for students in the treatment classes $\left(\mathrm{T}_{\text {Total }}\right)$ are shown in Table 5. When pre- and post measures of overall engagement for $\mathrm{T}_{\text {Total }}$ were compared, a statistically significant difference and positive effect size of 0.54 was found $(\mathrm{M}=0.527, \mathrm{SD}=0.694, t(45)=5.29, p<0.001)$. This effect size is considered medium (Cohen, 1992) and suggests that the MNT intervention had a positive impact on student engagement. All four of the engagement subscales of the DSES had statistically significant increases (Table 5).

For students in the treatment classes, $84 \%$ showed increases in self-reported overall engagement scores $(\mathrm{M}=0.44$, $\mathrm{SD}=0.816$, $\min =-1.46, \max =3.48$ ), as illustrated in Figure 2. For $\mathrm{T}_{\text {Total }}$ a comparison of pre-intervention scores and post-intervention scores shows that while engagement and all subscales increased significantly, the greatest increase occurred for the agentic engagement subscale (Figure 3).

Table 5. Pre- and post-DSES Scores for treatment students $\left(\mathrm{T}_{\mathrm{Total}}\right)$

\begin{tabular}{|c|c|c|c|c|c|c|c|c|c|}
\hline & \multirow[b]{2}{*}{$\mathrm{N}$} & \multicolumn{2}{|l|}{ Pre } & \multicolumn{2}{|l|}{ Post } & \multirow[b]{2}{*}{$t$} & \multirow[b]{2}{*}{ df } & \multirow[b]{2}{*}{ Sig. } & \multirow[b]{2}{*}{ Cohen d } \\
\hline & & Mean & Std. deviation & Mean & Std. deviation & & & & \\
\hline Engagement & 46 & 3.05 & 0.079 & 3.57 & 0.080 & 5.209 & 45 & $<0.001 * * *$ & 0.54 \\
\hline Emotional & 46 & 2.96 & 0.756 & 3.68 & 0.659 & 6.216 & 45 & $<0.001 * * *$ & 0.65 \\
\hline Behavioral & 46 & 3.39 & 0.093 & 3.73 & 0.618 & 2.868 & 45 & $0.006^{* *}$ & 0.38 \\
\hline Agentic & 46 & 2.78 & 0.087 & 3.60 & 0.836 & 6.991 & 45 & $<0.001 * * *$ & 0.73 \\
\hline Cognitive & 46 & 3.12 & 0.084 & 3.44 & 0.947 & 2.936 & 45 & $0.005 * *$ & 0.31 \\
\hline
\end{tabular}

Note. $* *$ significant at $\mathrm{p}=0.01 ; * *$ significant at $\mathrm{p}=0.001$.

Agentic engagement represents student self-advocacy such as asking questions and telling the teacher which learning activities best fit the student. 


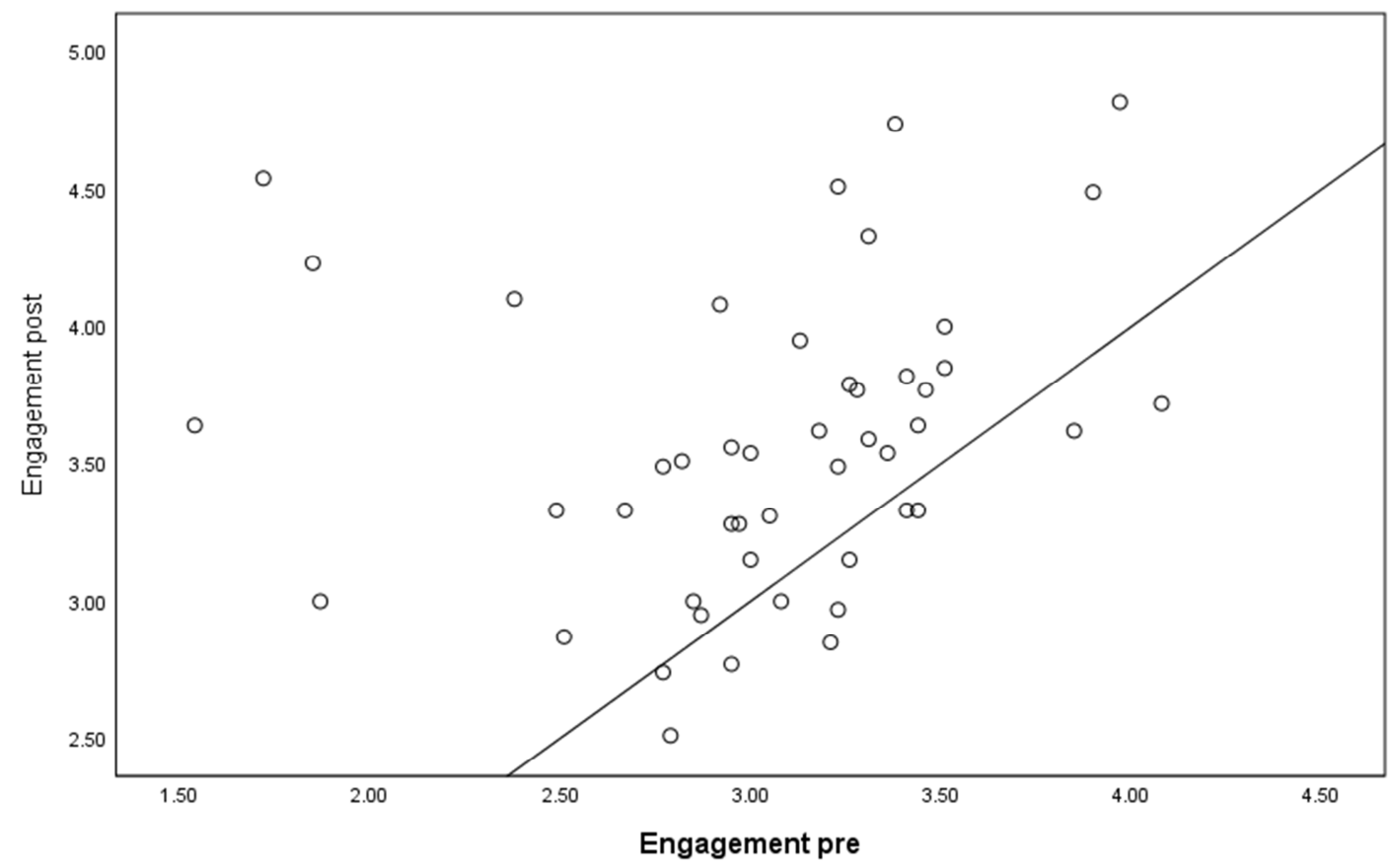

Figure 2. Comparison of Engagement scale post-intervention and pre-intervention for treatment students. The straight line represents engagement-post=engagement-pre (no change after the instructional intervention)

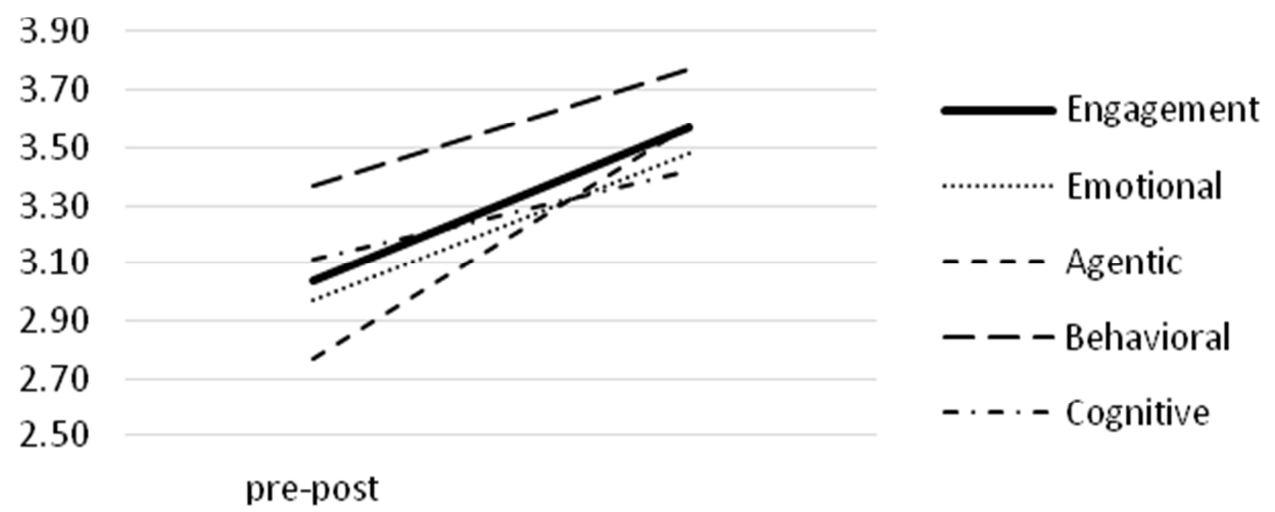

Figure 3. Changes in Engagement and subscales for treatment students' pre-intervention and post-intervention.

Overall and all subscales significant

In Figure 3, the left endpoints represent average treatment student scores prior to the MNT intervention, and the right endpoints represent average treatment student scores after the intervention. The lines are trend lines only, and are not meant to indicate that engagement increased in a linear manner. This Is not the case. Engagement is task can context specific, so it would not be expected to increase linearly.

The control class pre-post results were considerably different (Table 6). Neither the overall engagement scores nor any of the subscales showed significant differences. 
Table 6. Pre- and post-DSES overall and subscale scores for control class

\begin{tabular}{lllllllll}
\hline & & \multicolumn{9}{c}{ Pre } & \multicolumn{3}{c}{ Post } & & Sig. \\
\cline { 2 - 6 } & $\mathrm{N}$ & Mean & Std. deviation & Mean & Std. deviation & & & df \\
\hline Engagement & 22 & 3.38 & 0.722 & 3.61 & 0.538 & 1.100 & 21 & 0.284 \\
Emotional & 22 & 3.70 & 0.693 & 3.84 & 0.590 & 0.873 & 21 & 0.392 \\
Behavioral & 22 & 3.56 & 0.600 & 3.63 & 0.651 & 0.380 & 21 & 0.708 \\
Agentic & 22 & 3.32 & 0.680 & 3.60 & 0.593 & 1.916 & 21 & 0.069 \\
Cognitive & 22 & 3.49 & 0.571 & 3.30 & 0.723 & -0.998 & 21 & 0.329 \\
\hline
\end{tabular}

\subsubsection{Treatment-Control Comparisons}

When treatment-control comparisons of engagement were made prior to the MNT intervention, the control class showed a significant differential advantage over $\mathrm{T}_{\text {Total }}(\mathrm{M}=0.34, \mathrm{SD}=0.158, \mathrm{t}(66)=2.140, p=0.036)$. After the MNT intervention, no significant differences were found for the control class $(\mathrm{M}=-0.24, \mathrm{SD}=1.024, t(21)=-1.100$, $p=0.284$ ) compared to the treatment classes. Thus, after the MNT intervention, the level of engagement for both treatment classes had increased, while no change was found for the control class.

\subsubsection{Qualitative Findings}

All students interviewed specifically mentioned the rich assessment task as very engaging, since it was active, hands-on, employed manipulatives and technology, and student groups for the data collection stage. Another strategy specifically mentioned by the interviewees was the teacher's use of individual student whiteboards. Comments on this instructional strategy identified uniqueness, immediate feedback, and an active learning stance in the classroom.

Grounded theory analysis (Charmaz, 2014) of student interview comments identified several themes. Fun was a theme commonly cited in the interviews. The MNT intervention was considered significantly more fun than the students' usual math classes. A second theme was energy, since the interviewees felt that the classroom exhibited more energy and activity levels than normal. This energy was attributed to increased social activities and variety of learning opportunities. Increased use of student groupings was a third theme, identified by all five interviewees. Again, this was contrasted with the usual math classes, which tended to be teacher-directed and utilized students sitting in rows and working individually. The use of hands-on activities, manipulatives, and technology was a fourth theme. While the school was in a BYOD board and technology was routinely employed, activities using manipulatives such as algebra tiles and other hands-on materials was seen as a positive change by the student interviewees. Student comments identified this as a fourth theme that influenced engagement, variety of activities, and classroom organization changes. Finally, students identified positive changes in work habits based on interesting and relevant relationships between the mathematical content and the real world. Three of the students interviewed indicated that prior to the MNT intervention, their approach to classwork and homework was somewhat sporadic since they found the mathematical content to be uninteresting and sometimes boring. Figure 4 provides sample student comments on themes related to engagement. Specific references were made to the increased social atmosphere in the class due to numerous group activities. When asked to identify one activity that was very engaging, Wendy stated

When we did a bunch of activities in little groups and we passed them around the class. Because we got to work on the questions with other people. So, you got to put in your input but also have them. So, if you didn't know something, they might know it and if you complete the question the class you felt you were really pleased and tired. (Post-intervention interview, May 7, 2018)

As can be seen in Figure 4, Lina echoed this stance. This contrasted with the students' views that usually math classes were routine and teacher-centred. At least three students felt that the active learning stance of the unit was a much better fit for their personal learning modality than the normal classroom routine which often employed a document camera and teacher-lead lessons; that their level of engagement was content and topic specific, in that they felt more engaged during some activities than others; and that there was an increased energy in the classroom compared to the normal classroom routine. Shelly (see Figure 5) commented on how this differed from the usual atmosphere in math class. Rob commented on this increased energy when he referred to his surprise that other students became more engaged: "I participate in class almost all the time. But what I've seen is more kids getting engaged. Kids around me that I don't expect to get engaged getting engaged. So that was interesting" (Post-intervention interview, May 8, 2018). This student's behaviour appeared to be contagious in that three students described other students in the class appearing to be more engaged than usual and that this behaviour seemed to influence additional students to become more engaged as well. Both the students and the 
teachers emphasized that engagement was task and context specific:

I liked the activities where you had to work with your peers. Obviously, it's a very different model than you usually do, come with the whole equation together so that was obviously [sic] you're forced to work with everybody else. So, think about it. I like working with others. It's interesting to see what they say. So, it kind of breaks [sic] my thoughts. Usually math class is not like social. (Dani, post-intervention interview, May 8, 2018)

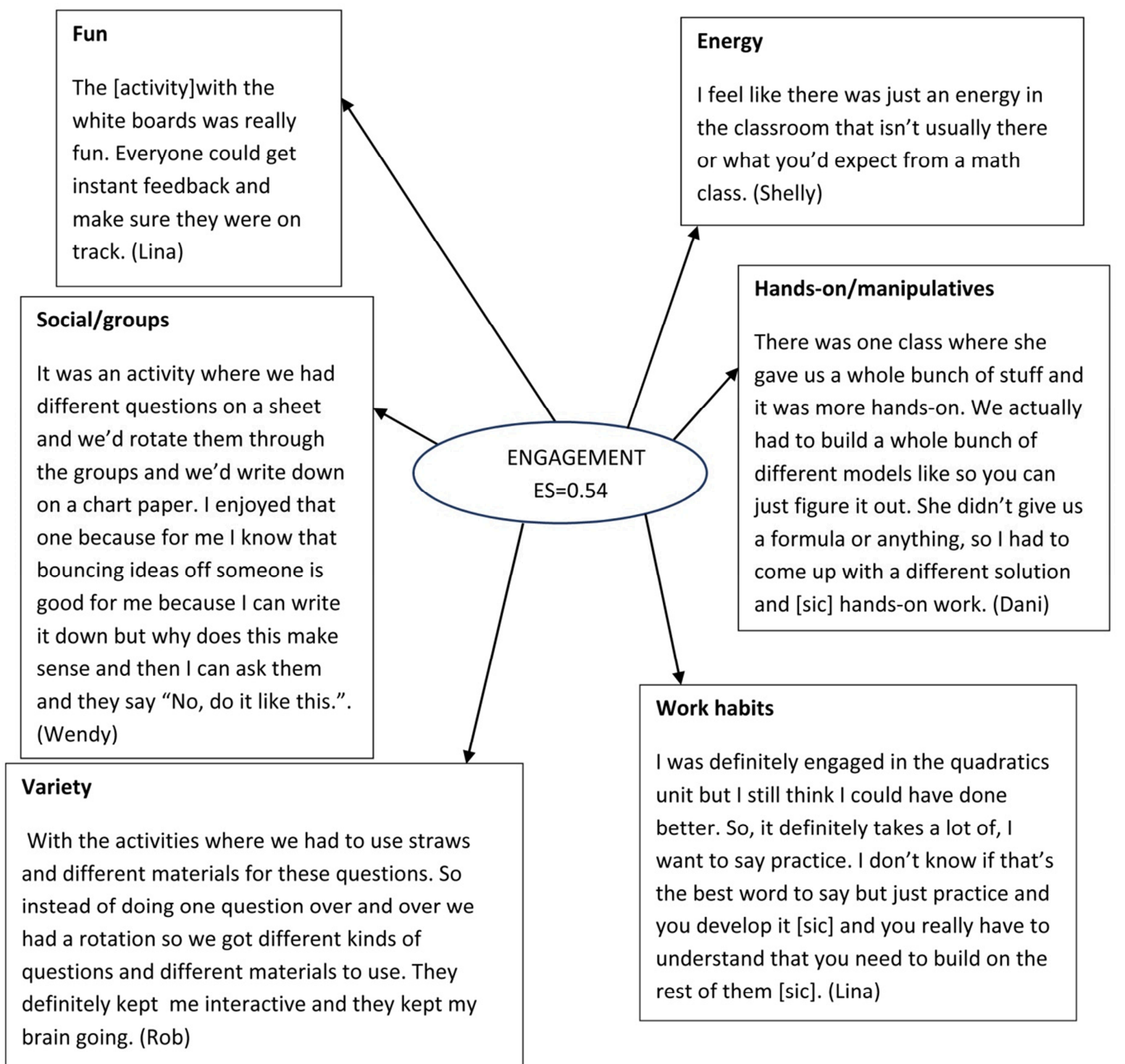

Figure 4. Student quotations reflecting aspects of MNT intervention that impacted on student engagement. Note. ES=effect size; All student quotations taken from post-intervention interviews, May 7 to May 9, 2018.

\section{Attitude}

The second dependent variable examined was student attitudes. Again, both quantitative and qualitative data were collected and analyzed.

\subsection{Quantitative Findings}

All students completed the ATMI both pre-and post the MNT intervention.

\subsubsection{Pre-post comparisons}

When pre-post comparisons were made for students in the treatment group, a significant positive effect size of 
0.32 was found $(\mathrm{M}=0.270, \mathrm{SD}=0.0870, \mathrm{t}(45)=3.110, p=0.003)$ for overall student attitudes. While overall attitude and all subscales increased, the only statistically significant increase in the subscales occurred for the self-confidence subscale (Table 7 and Figure 5).

Analysis of Figure 5 found that $76 \%$ of students in $\mathrm{T}_{\text {Total }}$ showed a positive increase in their attitudes towards mathematics. In addition, the magnitudes of the average increases for the attitude scales (Attitude post minus Attitude pre) were smaller $(\mathrm{M}=0.15, \mathrm{SD}=0.617, \min =-1.66, \max =1.94)$ than the magnitude of the average increases for the engagement scales (Engagement post minus Engagement pre), $\mathrm{M}=0.44, \mathrm{SD}=0.817$, $\min =-1.46$, $\max =3.48$. The differences in mean magnitudes between engagement changes and attitude changes was statistically significant $(\mathrm{M}=0.28, \mathrm{SD}=0.932, \mathrm{t}(68)=2.307, p=0.015)$. The pattern observed for the magnitudes of attitude changes was similar to the pattern for engagement, i.e., students who had the lowest attitude pre scores showed the largest increases in attitude post scores.

Table 7. Pre- and post-ATMI overall and subscale scores for $\mathrm{T}_{\text {Total }}$

\begin{tabular}{|c|c|c|c|c|c|c|c|c|c|}
\hline \multirow[b]{2}{*}{ Category } & \multirow[b]{2}{*}{$\mathrm{N}$} & \multicolumn{2}{|l|}{ Pre } & \multicolumn{2}{|l|}{ Post } & \multirow[b]{2}{*}{$\mathrm{t}$} & \multirow[b]{2}{*}{ df } & \multirow[b]{2}{*}{ Sig. } & \multirow[b]{2}{*}{ Cohen d } \\
\hline & & Mean & Std. deviation & Mean & Std. deviation & & & & \\
\hline Attitude & 46 & 3.56 & 0.772 & 3.83 & 0.504 & 3.110 & 45 & $0.003 * *$ & 0.32 \\
\hline Value & 46 & 3.82 & 0.088 & 3.95 & 0.725 & 1.556 & 45 & 0.123 & -- \\
\hline Enjoyment & 46 & 3.67 & 0.105 & 3.80 & 0.090 & 1.243 & 45 & 0.220 & -- \\
\hline Motivation & 46 & 3.62 & 0.103 & 3.69 & 0.091 & 0.928 & 45 & 0.358 & -- \\
\hline Self Confidence & 46 & 3.56 & 0.101 & 3.84 & 0.087 & 3.138 & 45 & $0.003 * *$ & 0.33 \\
\hline
\end{tabular}

Note. ${ }^{* *}$ significant at $\mathrm{p}=0.01$.

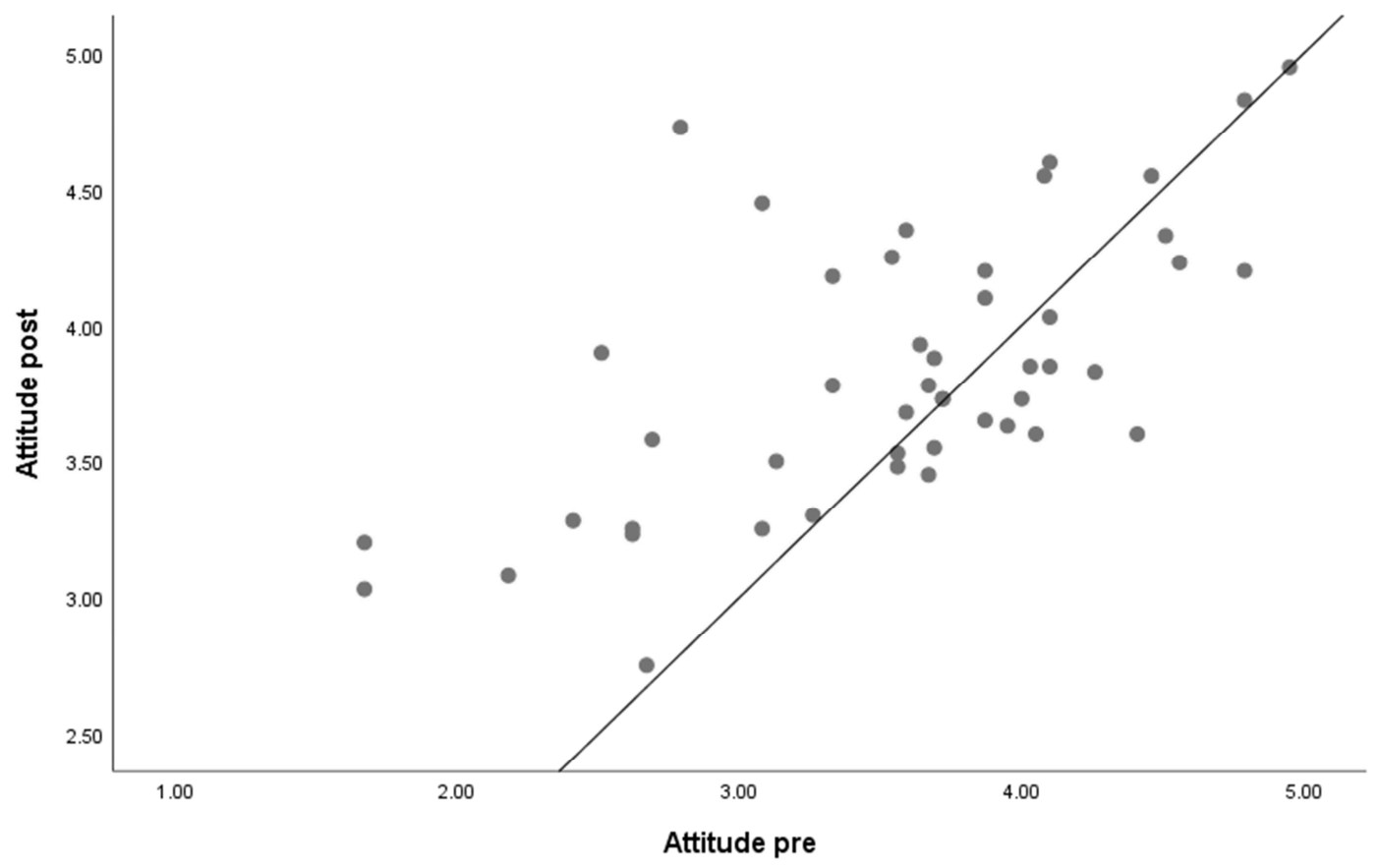

Figure 5. Comparison of attitude scale post-intervention and pre-intervention for treatment students Note. The straight line represents attitude-post=attitude-pre (no change after the instructional intervention). 


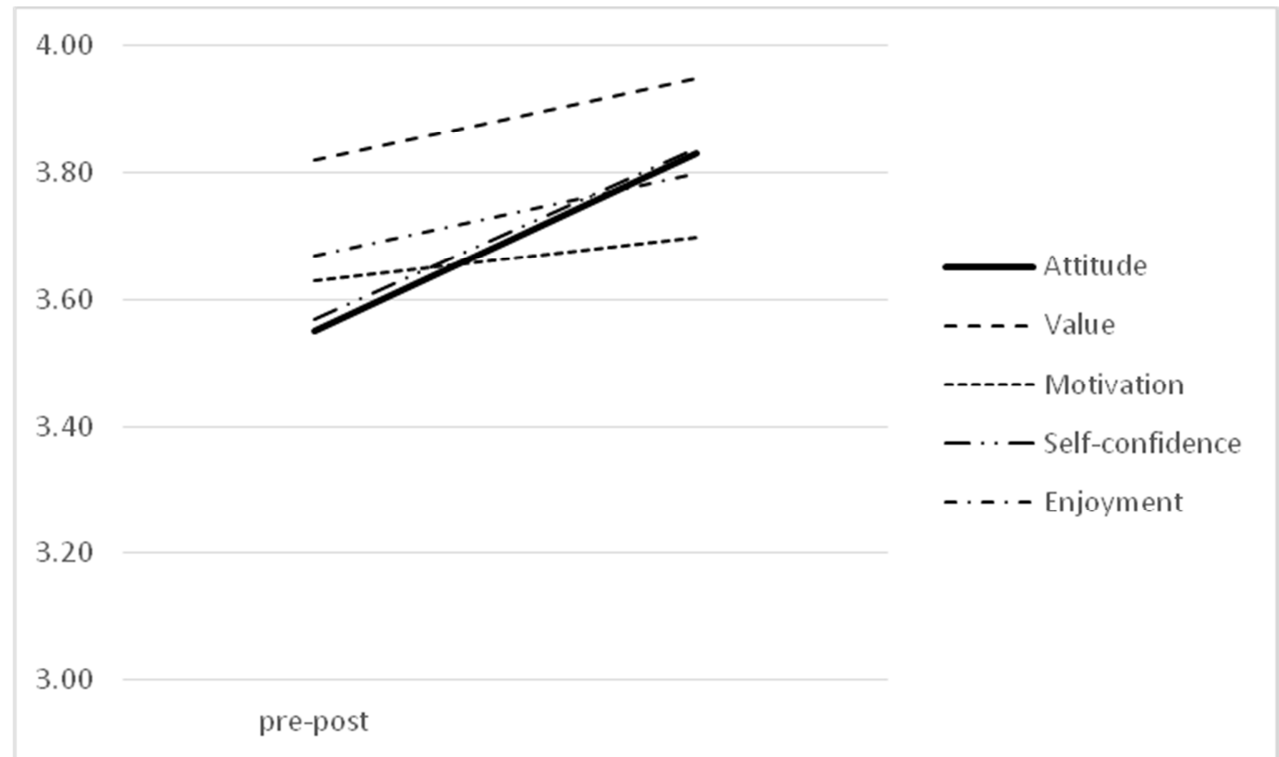

Figure 6. Changes in Attitude and subscales for $\mathrm{T}_{\text {Total }}$ pre-intervention and post-intervention

Note. Only the overall attitude scale and the self-confidence subscale are statistically significant.

For the control class (Table 8$)$ the only significant change was in the self-confidence subscale $(\mathrm{M}=3.38$, $\mathrm{SD}=0.660, \mathrm{t}(21)=-2.608, p=0.016)$ and showed a negative change in attitudes toward mathematics over the time the unit was taught. This may reflect that the content of the quadratic relations unit was more difficult than the previous unit on linear systems.

Table 8. Pre- and post-ATMI overall and subscale scores for control class

\begin{tabular}{|c|c|c|c|c|c|c|c|c|}
\hline \multirow[b]{2}{*}{ Category } & \multirow[b]{2}{*}{$\mathrm{N}$} & \multicolumn{2}{|l|}{ Pre } & \multicolumn{2}{|l|}{ Post } & \multirow[b]{2}{*}{$\mathrm{t}$} & \multirow[b]{2}{*}{$\mathrm{df}$} & \multirow[b]{2}{*}{ Sig. } \\
\hline & & Mean & Std. deviation & Mean & Std. deviation & & & \\
\hline Attitude & 22 & 3.55 & 0.651 & 3.45 & 0.569 & -0.732 & 21 & 0.472 \\
\hline Value & 22 & 3.63 & 0.513 & 3.63 & 0.513 & \# & 21 & \# \\
\hline Enjoyment & 22 & 3.39 & 0.579 & 3.42 & 0.657 & 0.588 & 21 & 0.563 \\
\hline Motivation & 22 & 3.16 & 0.734 & 3.15 & 0.743 & -1.000 & 21 & 0.329 \\
\hline Self-confidence & 22 & 3.45 & 0.679 & 3.38 & 0.660 & -2.608 & 21 & $0.016^{*}$ \\
\hline
\end{tabular}

Note. $\mathrm{t}$ and significance cannot be computed since mean difference is 0 ; * significant at $\mathrm{p}=0.05$

\subsubsection{Treatment-Control Comparisons}

Prior to the MNT intervention, no significant differences in attitudes were observed between the control class and $\mathrm{T}_{\text {Total }}(\mathrm{M}=-0.007, \mathrm{SD}=0.192, t(66)=-0.037, p=0.970)$. When treatment-control comparisons were made after the MNT intervention, $\mathrm{T}_{\text {Total }}$ showed a statistically significant increase in attitude scores compared to the control class $(\mathrm{M}=0.381, \mathrm{SD}=0.1372, t(66)=2.781, p=0.007)$.

\subsection{Qualitative Findings}

All students who were interviewed indicated that the increased social culture of the classroom positively affected their attitude toward mathematics, even though two of the interviewees came into the unit with decidedly negative attitudes towards the subject. In their interviews, the students indicated that the increased number of activities was different than the norm and that the uniqueness of this unit positively impacted their attitudes. The student responses reflected that attitude is a complex construct; interactions of attitude with other factors - such as prior and current achievement, peer and family effects, future plans, and other activities such as sports or the arts-all influenced the students' attitudes toward mathematics.

Additional themes identified in student interviews included student comfort levels (related to teacher or classroom culture) and frustration based on inadequate understanding of material. Perceived teacher care was also identified:

[Ms. Beckham] is a great teacher. You know that she cares about you. I feel like she teaches just the right 
way. A high school teacher like she doesn't hold your hand. But she doesn't push you off a cliff, you know. (Shelly, post-intervention interview, May 7, 2018)

Students often mentioned that classes in this unit were more "fun," although this may reflect a comingling of attitudes and engagement. Figure 7 provides additional aspects of the MNT intervention influence on attitudes based on student interviews. Grounded theory analysis resulted in attitude-related themes being identified in student interviews as self-confidence, teacher style, interest, persistence, and motivation to continue taking mathematics. Increased self-confidence was cited by four students, based on changes in classroom organization from teacher-centred to the use of small groups and activities that addressed different learning modalities.

A second theme was related to teacher style, with the teacher becoming more participatory with students in the learning process. Increased interest was a major theme identified. All five students identified the variety of activities and the linking of mathematical content to real-world situations as resulting in more interesting classes. An additional theme was persistence. Students stated that they tended to persist in solving problems related to the MNT intervention, and that they worked to achieve understanding of the mathematical content.

Finally, student interviewees stated that participating in the MNT intervention had increased their motivation to take additional mathematics courses, both in the senior grades of high school and potentially at university. Figure 7 provides some selected student interview responses concerning these themes.

One repeated comment about the MNT intervention was the positive response to asking students' opinions. Four of the five students indicated that they really liked being asked about their levels of engagement and attitudes, and that no one had ever asked them about these attributes before:

I liked a lot of your activities. I also liked the fact that you're interested in what the students think. I feel like sometimes our opinion gets overlooked and we kind of just get passed along to Grade 12. (Lina, post-intervention interview, May 8, 2018)

The students also liked specific personal goal-setting activities during the unit. Again, no one had ever asked them to set personal goals before this unit. 


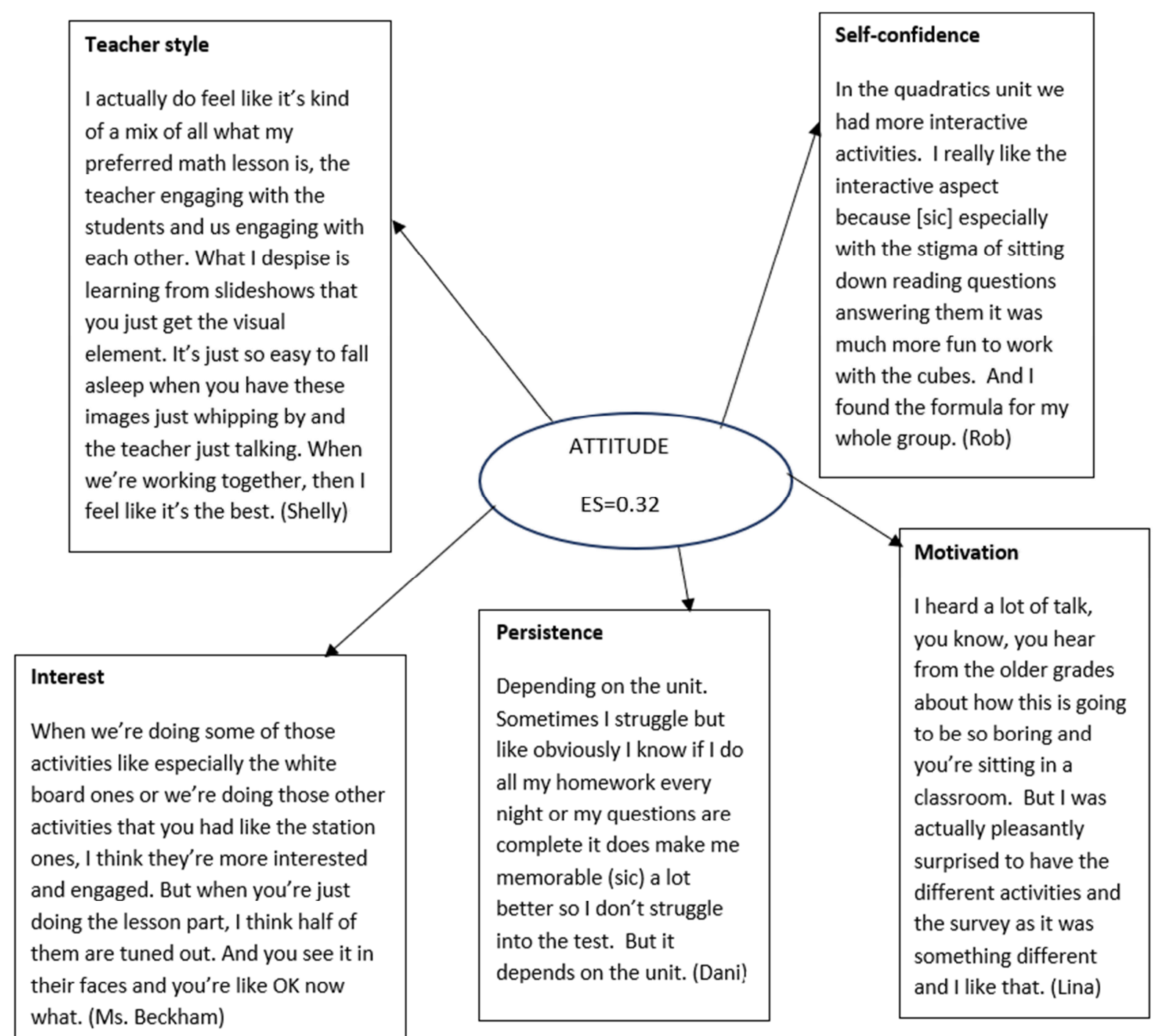

Figure 7. Quotations indicating different aspects of MNT intervention impact on student attitudes

Note. ES=effect size; All student quotations taken from post-intervention interviews, May 7 to May 9, 2018. Teacher quotations taken from post-intervention interviews May 9, 2018.

\section{Discussion}

\subsection{Engagement}

The hypothesis that students in the MNT intervention classes would demonstrate significant increases in student engagement compared to students in the control class was supported. Paired $t$-tests found a significant effect size of 0.54 despite the relatively short duration of this intervention of approximately 30 instructional days. The validity of Marzano's ordering of self, metacognitive, and cognitive systems was somewhat supported, notably by student and teacher comments that when students engaged in a task, they were more likely to persist and make a sustained effort, especially if the task was viewed as interesting and engaging. This impact on student engagement was most pronounced with students who initially reported being less engaged in their normal classroom activities, but who indicated dramatically greater levels of engagement during the MNT intervention.

Both student and teacher comments reinforced literature that engagement is context and task specific and that engagement can be positively influenced in the short term (DeBellis \& Golding, 2006). Features of the MNT intervention such as student social interactions, group activities, student-centred instructional strategies that employed hands-on activities, manipulatives, and technology (reform mathematics principles) were confirmed as positively impacting student engagement, consistent with existing research (Lassinantti, Stahlbrost, \& Runardotter, 2019; Smith \& Star, 2007). The instructional strategies in this study that employ an active, social 
stance for students have been found to have long-lasting effects on student engagement (Moyer et al., 2018; Smith \& Star, 2007). The literature states that teacher practices must be intentional with respect to student engagement (Skilling et al., 2016); this current study's explicit focus on engagement and attitude provides additional research evidence of this instructional stance.

Another consideration is whether teacher style fosters student engagement. For example, Reeve and Jang (2006) identify autonomy-supportive behaviour by teachers as positively influencing student engagement. In the present study, Ms. Beckham was very strong on classroom structural dimensions, but less so on autonomy-supportive dimensions. Choice, a major determinant of autonomy support, was rarely provided except during the MNT intervention. While Ms. Beckham stated, "I do a lot of investigations," the use of the possessive pronoun "I" was telling. She did not say that her students did a lot of investigations, rather "I" did them, offering little or no choice to the students. This teacher's style was not congruent with the overall intent and many of the activities of the MNT intervention. However, Ms. Beckham made an effort to implement the MNT intervention with high fidelity of implementation.

Jang, Reeve, and Deci (2010) further identify three teacher instructional behaviours that are autonomy supportive for students: use non-controlling informational language, acknowledgement of students' perspective and feelings, and support of students' inner motivations. Jang et al. (2010) also identify three dimensions of classroom structure that support student engagement: presenting clear, explicit and detailed instructions; guiding students' ongoing activities; and giving constructive feedback. Based on classroom observations and teacher interview comments, Ms. Beckham's teaching style demonstrated limited congruence with the autonomy supportive dimensions while showing greater congruence with the structural dimensions. It could be speculated that effect sizes for this study may have been significantly greater if the teacher's style was more congruent to the style advocated for in the MNT intervention.

Bodovski and Farkas (2007) identified student engagement as having positive effects on student attitudes in mathematics. This was observed in the current study, with students who reported larger levels of engagement also reporting positive gains in attitudes towards mathematics, although the magnitude of those attitude gains was smaller than the corresponding increases in engagement. Collie and Martin (2007) found that increased gains in overalls engagement also mitigated gains in student agency. Again, this was observed in the current study, as student agency showed that largest gains compared to other dimensions of student engagement.

Marks (2000) claims that the links between engagement and achievement are sparse, and that engagement stands as a goal of education, separate from any potential relationship to student achievement. This stance is consistent with Collie and Martin (2017) who cite engagement as a goal of education whether or not it impacts other educational variables. This decoupling of engagement and achievement has important implications for life-long learning, as an espoused goal of education (Fredricks et al., 2004). Therefore, this study adds to the existing research on the importance of engagement in mathematics, as well as to the discussion relating engagement to mathematics achievement.

\subsection{Attitude}

The hypothesis that students in the MNT intervention classes would demonstrate significant increases in student attitudes towards mathematics compared to students in the control class was supported. The positive effect size of 0.32 for attitude found from paired $t$-tests was approximately $60 \%$ of the effect size for engagement, demonstrating perhaps that while engagement appears to be linked to short term emotions such as interest, attitude is less malleable. Again, this is consistent with existing research. According to McLeod (1992), repeated positive experiences over time would be required in order to result in significant changes in student attitudes. Further, attitude is quite resilient and difficult to modify in the short term (Di Martino \& Zan, 2010). The results for changes in student attitude supported the MNT intervention's structure, paying attention to student affective dimensions and explicitly inquiring into student attitudes for both individual activities and lessons as well as longer term effects on student attitudes towards mathematics.

The student and teacher comments in this study also reaffirmed that attitude is a complex multi-faceted construct with numerous modifier variables, including: perceived teacher care, student personal comfort levels, level of difficulty of the content being studied, and active instructional strategies. These findings were consistent with existing research (Mata et al., 2012). The instructional strategies employed in this intervention had a positive impact on student attitudes, congruent with existing literature (Domino, 2009; Vandecandelaere et al., 2012). Domino (2009) also found that teacher care and ensuring student understanding positively influenced student attitudes, and this study echoed those results. Instructional strategies in this study, similar to those identified for encouraging student engagement, also positively influenced student attitudes (Elçi, 2017). Other factors 
identified in the literature that positively influence student attitude towards mathematics: perceived teacher care (Cooper \& Miness, 2014); teachers' displays of enjoyment (Frenzel et al., 2009); teacher fairness (Mata et al., 2012); and classroom climate, especially social climate (Kunter et al., 2008) were all identified by students in this study as influencing their personal attitudes towards mathematics.

Student attitudes in this study were also influenced by the relative difficulty of the unit, which was perceived as being more difficult than the previous unit of study as well as the level of difficulty of the previous year's mathematics content. This is congruent with Elçi (2017) who found an inverse relationship between attitude and the level of difficulty of mathematical content studied, so that more difficult content would result in more negative attitudes towards mathematics.

\subsection{The MNT Intervention and Reform Mathematics}

The MNT intervention was most effective for students who initially reported low levels of engagement and for students who reported more negative attitudes towards mathematics This effect may be explained by the more active, reform mathematics instructional strategies employed by the MNT intervention. These instructional strategies involve real-world connections, hands-on activities, students working in groups, and using manipulatives to increase student involvement. Such strategies were found to increase and sustain student engagement (Moyer et al., 2018; Smith \& Star, 2007). In the MNT intervention, these strategies had the greatest impact on the most disengaged students and students with negative attitudes. It could be argued that these students' learning styles were a much better fit for the instructional strategies in the MNT intervention than the teacher-centred instructional strategies usually employed by Ms. Alford and Ms. Beckham. This result provides supporting evidence of the efficacy of reform mathematics strategies and emphasizes that such strategies may have the greatest impact on students who most need to become more reengaged, as well as students with more negative attitudes towards mathematics.

\section{Implications for Theory}

As noted above, this study adds to the literature on the resilience of attitudes toward mathematics as well as the inverse relationship between attitudes and difficulty of content. This study also adds to the debate concerning the link between engagement and achievement, indicating that further studies need to be done to better determine the nature of this relationship. The study also confirms the importance of intentionally considering affective dimensions, and structuring classroom interventions that positively influence student engagement.

\section{Implications for Practice}

There are several audiences with respect to implications for practice. These audiences include policy makers, educational researchers, classroom teachers and teacher educators.

\subsection{Policy}

First, for policy makers, this study supports a student-centred philosophy and demonstrates its effectiveness in engaging students as espoused by the Ontario Ministry of Education (2005) for mathematics. However, consideration must be given to additional professional learning for teachers in order to improve teacher understanding and assimilation of the principles of student-centred learning.

Secondly, this study emphasizes the need to consider student affective dimensions when setting policy for mathematics. Motivation and other affective dimensions have been shown to positively influence mathematics students' performance, widely construed, especially when measuring student engagement and attitudes (Schoenfeld, 2015). This is an area that needs to be rectified and is especially important at this time since the mathematics policy documents are currently under revision based on the 7-year cyclic review established by the Liberal Government in 2005. A search of current mathematics curriculum documents (Ontario Ministry of Education, 2005, 2007) found no mentions of motivation, attitude, engagement, self-efficacy, self-confidence, enjoyment, persistence. One mention of value was found, but only in reference to credit value. There are opportunities here since the mathematics curriculum is also currently undergoing a 4-year revision by the Ontario Ministry of Education (Conservative government). First, there is an opportunity to broaden the definition of achievement beyond mathematics content, to include affective dimensions that have been shown to be important for student growth and well-being (Kuntze \& Dreher, 2015). Secondly, explicitly including affective dimensions (such as positively changing student engagement and student attitudes) in overall and specific expectations in the mathematics curriculum policy documents will not only raise the profiles of these concepts with respect to teachers, as they become explicit expectations of instruction; it will signal to the broader education community that such affective dimensions are important and must be addressed. There are indications in the popular press that this current 4-year revision by the Progressive Conservative government will take 
student attitudes into account.

Too many adults, including plenty of teachers (and parents) don't like or feel comfortable with math. That sentiment is far too easily passed on to impressionable kids. And research shows that students' attitudes toward math influences their outcomes. ("Let's Be Smart on Math Fixes", 2019, p. A12)

However, to date there has been no curriculum document released by the Ontario Ministry of Education that explicitly recognizes the connections between student attitudes towards mathematics and student competence in mathematics (Ontario Ministry of Education, 2019a, 2019b).

\subsection{Schools and Teachers}

For schools and classroom teachers, the MNT instructional intervention in this study provides an exemplar of theory to practice, where changes in student engagement and/or student attitudes are the goals; it also provides a template for developing similar complete units or activity packages. The instructional strategies utilized by the classroom intervention in this study provide evidence of the efficacy of reform mathematics principles (Smith \& Star, 2007) such as the appropriate use of manipulatives; making real-world connections for students; supporting student autonomy through groups and choice; active rather than passive student participation. The results of this study also provide support for the principles of self-determination theory (Deci \& Ryan, 2008): autonomy, competence, and relatedness: autonomy support through choice; competence through teaching for understanding and supporting students' different learning modalities; and relatedness through the use of student groups.

In organizational theory, teaching is identified as a professional bureaucracy (Mintzburg, 1989). This describes a structure in which overall policy and direction is given centrally but individual teachers experience a wide degree of independence in implementing policies. In such a structure, teachers need to be convinced of the efficacy of new policies before acceptance and true implementation will occur. To support change in this type of organization, dissemination of "success stories" and best practices based on actual classroom implementations of research-affirmed strategies is needed. Only when teachers see such strategies positively impacting students can teachers be expected to accept and implement changes in their own professional practice.

If development of a full unit or course based on the MNT structure is not feasible, teachers could consider simpler interventions. For example, the current study utilized brief student responses to questions such as "Was today's lesson interesting for you?" and "Rate how valuable today's topic was for you." Brief anonymous responses provide teachers with guidelines for modifying instructional strategies, while also motivating students to consider more fully what types of lessons are most productive for them personally. This increase in student agency has significant potential to increase student engagement (Deci \& Ryan, 2008), at very little cost in teacher planning time.

\subsection{Educational Researchers}

Student attitudes towards mathematics is a burgeoning area of study that has attracted considerable interest in recent decades (e.g., Crano \& Prislin, 2008; Pepin \& Roesken-Winter, 2015). In addition, related constructs such as beliefs (McLeod \& McLeod, 2002), interest (Renninger, Nieswandt, \& Hidi, 2015), affect (Forgas, 2008), and emotions (Radford, 2015) have all received scrutiny. This study adds to the literature in the areas of student attitudes and engagement in mathematics and provides a classroom study which can be utilized as an exemplar.

When constructing their own classroom studies, researchers must also give consideration to logistical constraints, whereby some school boards receive multiple requests for classroom studies while other boards receive few or none. This could be alleviated if researchers were encouraged to consider the possibility of conducting their research in school districts that would be more open to accepting classroom studies and have the capacity to do so. Such a policy could be supported by the Ministry of Education, which could disseminate information about research projects that are currently underway in each board. Financial support could also be offered to researchers for conducting their studies in non-local or remote boards of education. The results would be a richer research palette as well as broader dissemination of theory-into-practice across the province.

A notable concern is that often teacher volunteers come only from the most enthusiastic and dedicated teachers. While this mitigates for stronger implementation fidelity, it also may bias results since these teachers are not necessarily representative of the teacher cohort as a whole. Coupled with the naturalistic setting in classrooms, this has implications for generalizability (Kruskal \& Mosteller, 1979).

Finally, practitioners and researchers must recognize the need to control for, as much as possible, extraneous or confounding factors that may influence outcomes. For example, in the current study the level of difficulty of the mathematical content of the unit may have impacted student achievement and may have influenced engagement and attitude as well. 


\section{Implications for Future Research}

Based on this study, there are a number of additional implications for future research. First, this study occurred in a single secondary school, and needs to be replicated in other venues, with different students, classes and school characteristics. In addition, longitudinal studies utilizing similar instructional interventions need to be developed and implemented for longer periods of time. Will there be diminishing returns to engagement gains over a longer period, or will gains be proportional to the time period? Since attitude is more malleable in the intermediate and longer term, will greater positive gains in student attitudes be observed when the duration of interventions is increased? Initially, a classroom intervention based on MNT could be developed for the remaining three units of the Grade 10 Academic Mathematics course and implemented for a full semester. This would allow a more fulsome examination of the variables of interest as well as providing a substantial body of exemplar materials.

In the current study that focused on engagement and attitude, an interaction effect between the two variables was not examined. Implementation of a full-semester classroom intervention would enable investigation of whether there was an interaction effect, and if so, what form did this interaction take. The various moderator variables affecting attitude and whether there were interaction effects among the variables could also be examined.

In addition, the question whether positive student responses to self-reported surveys translate into changes in effort, persistence, self-efficacy, or achievement could be examined. Triangulation of such self-reported data with other measures would increase reliability and generalizability of findings.

Awareness of student affective dimensions in mathematics teaching is important to benefiting both student learning of content as well as promoting more positive attitudes towards mathematics among students (Pepin \& Roesken-Winter, 2015). Affect in mathematics learning has become a major research area over the last several years (Hannula, 2015; Schoenfeld, 2015). It is unacceptable that comments such as "I was never good at math" are socially acceptable. Therefore, paying attention to student motivational factors must be included alongside pedagogical strategies that are research-affirmed and involve students in their own learning. Supports must be provided to inform teachers of current research, encourage implementation of both motivational and instructional strategies, and structure job-embedded support systems in jurisdictions across Canada. The Ontario Ministry of Education has supported job-embedded professional learning for over a decade (Irvine \& Telford, 2015). However, this job-embedded support needs to refocus on affective dimensions of student learning and provide teachers with instructional strategies that promote positive behaviours in student engagement and positive attitudes towards mathematics learning.

\section{References}

Archambault, I., Janosz, M., \& Chouinard, R. (2012). Teacher beliefs as predictors of adolescents' cognitive engagement and achievement in mathematics. Journal of Educational Research, 105(5), 319-328. https://doi.org/10.1080/00220671.2011.629694

Asante, K. O. (2012). Secondary students' attitudes towards mathematics. IFE PsychologIA, 20(1), 121-133.

Ball, D. L., \& Bass, H. (2003). Toward a practice-based theory of mathematical knowledge for teaching. In E. Simmt \& B. Davis (Eds.), Proceedings of the 2002 annual meeting of the Canadian Mathematics Education Study Group (pp. 3-14). Retrieved from https://files.eric.ed.gov/fulltext/ED529557.pdf

Bodovski, K., \& Farkas, G. (2007). Mathematics growth in early elementary school: Beginning knowledge, student engagement, and instruction. The Elementary School Journal, 108(2), 115-130. https://doi.org/10.1086/525550

Caskie, G., Sutton, M., \& Eckhardt, A. (2014). Accuracy of self-reported college GPA: Gender-moderated differences by achievement level and academic self-efficacy. Journal of College Student Development, 55(4), 385-390. https://doi.org/10.1353/csd.2014.0038

Charmaz, K. (2014). Constructing grounded theory (2nd ed.). Thousand Oaks, CA: Sage.

Clarkson, P. (2013, January). A paradox? Students' mathematical well-being. Poster session presented at the MERU Seminar Series, University of Ottawa, ON. Retrieved from http://meru-urem.ca/2013-5/

Collie, R., \& Martin, A. (2017). Students' adaptability in mathematics: Examining self-reports and teachers' reports and links with engagement and achievement. Contemporary Educational Psychology, 49, 355-366. https://doi.org/10.1016/j.cedpsych.2017.04.001

Conner, J. O., \& Pope, D. (2013). Not just robo-students: Why full engagement matters and how schools can promote it. Journal of Youth and Adolescence, 42(9), 1426-1442. 
https://doi.org/10.1007/s10964-013-9948-y

Conner, T. (2011). Academic engagement ratings and instructional preferences: Comparing behavioral, cognitive, and emotional engagement among three school-age student cohorts. Review of Higher Education and Self-Learning, 4(13), 52-66.

Cooper, K., \& Miness, A. (2014). The co-creation of caring student-teacher relationships: Does teacher understanding matter? The High School Journal, 97(4), 264-290. https://doi.org/10.1353/hsj.2014.0005

Cotic, M., \& Zuljan, V. (2009). Problem-based instruction in mathematics and its impact on the cognitive results of the students and on affective-motivational aspects. Educational Studies, 35(3), 297-310. https://doi.org/10.1080/03055690802648085

Crano, W., \& Prislin, R. (Eds). (2008). Attitudes and attitude change. New York, NY: Psychology Press.

DeBellis, V., \& Golding, G. (2006). Affect and meta-affect in mathematical problem solving: A representational $\begin{array}{llll}\text { perspective. Educational Studies in } & \text { Mathematics, 63(2), 131-147. }\end{array}$ https://doi.org/10.1007/s10649-006-9026-4

Deci, E., \& Ryan, R. (2008). Self-determination theory: A macrotheory of human motivation, development, and health. Canadian Psychology, 49(3), 182-185. https://doi.org/10.1037/a0012801

Deci, E., Vallerand, R., Pelletier, L., \& Ryan, R. (1991). Motivation and education: The self-determination perspective. Educational Psychologist, 26(3-4), 325-346. https://doi.org/10.1080/00461520.1991.9653137

Desimone, L., Smith, T., \& Frisvold, D. (2010). Survey measures of classroom instruction: Comparing student and teacher reports. Educational Policy, 24(2), 267-329. https://doi.org/10.1177/0895904808330173

Di Martino. P., \& Zan, R. (2010). "Me and maths": Towards a definition of attitude grounded in students' narratives. Journal of Mathematics Teacher Education, 13, 27-48. https://doi.org/10.1007/s10857-009-9134-z

Domino, J. (2009). Teachers' influences on students' attitudes toward mathematics. Research and Teaching in Developmental Education, 26(1), 32-54.

Dotterer, A., \& Lowe, K. (2011). Classroom context, school engagement, and academic achievement in early adolescence. Journal of Youth and Adolescence, 40, 1649-1660. https://doi.org/10.1007/s10964-011-9647-5

Ediger, M. (2012). Quality teaching in mathematics. Education, 133(2), 235-238.

Education Quality and Accountability Office. (2014, February). Tracking the longitudinal performance of students in mathematics (Research Bulletin \#13). Retrieved from http://www.ontla.on.ca/library/repository/ser/283868/2014no13feb.pdf

Elçi, A. (2017). Students' attitudes towards mathematics and the impacts of mathematics teachers' approaches on it. Acta Didactica Napocensia, 10(2), 99-108. https://doi.org/10.24193/adn.10.2.8

Forgas, J. (2008). The role of affect in attitudes and attitude change. In W. Crano \& R. Prislin (Eds). Attitudes and attitude change (pp.131-160). New York, NY: Psychology Press.

Fredricks, J., Blumenfeld, P., \& Paris, A. (2004). School engagement: Potential of the concept, state of the evidence. Review of Educational Research, 74(1), 59-109. https://doi.org/10.3102/00346543074001059

Frenzel, A., Goetz, T., Ludke, O., Pekrun, R., \& Sutton, R. (2009). Emotional transmission in the classroom: Exploring the relationship between teacher and student enjoyment. Journal of Educational Psychology, 101(3), 705-716. https://doi.org/10.1037/a0014695

Fung, F., Tan, C., \& Chen, G. (2018). Student engagement and mathematics achievement: Unraveling main and interactive effects. Psychology in Schools, 55(7), 815-831. https://doi.org/10.1002/pits.22139

Hannula, M. (2002). Attitude towards mathematics: Emotions, expectations and values. Educational Studies in Mathematics, 49(1), 25-46. https://doi.org/10.1023/A:1016048823497

Hannula, M. (2006). Motivation in mathematics: Goals reflected in emotions. Educational Studies in Mathematics, 63, 165-178. https://doi.org/10.1007/s10649-005-9019-8

Hannula, M. (2015). Reaction to Section 2: The relevance of affective systems and social factors: A commentary. In B. Pepin \& B. Roesken-Winter (Eds.), From beliefs to dynamic affect systems in mathematics education: Exploring a mosaic of relationships and interactions (pp. 269-281). New York, NY: Springer. 
https://doi.org/10.1007/978-3-319-06808-4_13

Harlow, L., DeBacker, T., \& Crowson, H. M. (2011). Need for closure, achievement goals, and cognitive engagement in high school students. The Journal of Educational Research, 104, 110-119. https://doi.org/10.1080/00220670903567406

Hattie, J. (2009). Visible learning. Oxford, UK: Routledge. https://doi.org/10.4324/9780203887332

Hattie, J., \& Yates, G. (2014). Visible learning and the science of how we learn. Oxford, UK: Routledge. https://doi.org/10.4324/9781315885025

Irvine, J. (2018a). A framework for comparing theories related to motivation in education. Research in Higher Education Journal, 35, 1-30. Retrieved from https://eric.ed.gov/?id=EJ1194268

Irvine, J. (2018b). Relationship between teaching experience and teacher effectiveness: Implications for policy decisions. Journal of Instructional Pedagogies, 22, 1-19. Retrieved from http://www.aabri.com/manuscripts/182906.pdf

Irvine, J., \& Telford, W. (2015). Mathematics coaching and the coaching cycle: The Math GAINS project. Journal of Case Studies in Education, 7, 1-16.

Jang, H., Reeve, J., \& Deci, E. (2010). Engaging students in learning activities: It is not autonomy support or structure but autonomy support and structure. Journal of Educational Psychology, 102(3), 588-600. https://doi.org/10.1037/a0019682

Johnson, R. B., \& Onwuegbuzie, A. J. (2004). Mixed methods research: A research paradigm whose time has come. Educational Researcher, 33(7), 14-26. https://doi.org/10.3102/0013189X033007014

Koller, O., Baumert, J., \& Schnabel, K. (2001). Does interest matter? The relationship between academic interest and achievement in mathematics. Journal for Research in Mathematics Education, 32(5), 448-470. https://doi.org/10.2307/749801

Krupa, K. M. (2017). Perceived emotional support in the teacher-student relationship (pp. 38-47). Proceedings of the 7th Annual International Conference on Education and e-Learning, 2017.

Kruskal, W., \& Mosteller, F. (1979). Representative sampling I: Non-scientific literature. International Statistical Review, 47(1), 13-24. https://doi.org/10.2307/1403202

Kunter, M., Tsai, Y., Klusmann, U., Brunner, M., Krauss, S., \& Baumert, J. (2008). Students' and mathematics teachers' perceptions of teacher enthusiasm and instruction. Learning and Instruction, 18(5), 468-482. https://doi.org/10.1016/j.learninstruc.2008.06.008

Kuntze, S., \& Dreher, A. (2015). PCK and the awareness of affective aspects reflected in teachers' views about learning opportunities-A conflict? In B. Pepin \& B. Roesken-Winter (Eds.), From beliefs to dynamic affect systems in mathematics education: Exploring a mosaic of relationships and interactions (pp. 295319). New York, NY: Springer. https://doi.org/10.1007/978-3-319-06808-4_15

Lassinantti, J., Stahlbrost, A., \& Runardotter, M. (2019). Relevant social groups for open data use and engagement. Government Information Quarterly, 36(1), 98-111. https://doi.org/10.1016/j.giq.2018.11.001

Li, Y., \& Lerner, R. (2013). Interrelations of behavioral, emotional, and cognitive school engagement in high school students. Journal of Youth and Adolescence, 42, 20-32. https://doi.org/10.1007/s10964-012-9857-5

Liljedahl, P. (2014, May). Bootstrapping thinking: The role of engaging mathematical tasks. Paper presented at the Canadian Mathematics Education Forum, Ottawa, ON.

Lim, S. Y., \& Chapman, E. (2013). Development of a short form of the attitudes toward mathematics inventory. Educational Studies in Mathematics, 82, 145-164. https://doi.org/10.1007/s10649-012-9414-x

Maat, S., Zakaria, E., Nordin, N., \& Embi, M. (2010). Engineering technology students' mathematics beliefs and attitude towards mathematics. The International Journal of Learning, 17(3), 201-210. https://doi.org/10.18848/1447-9494/CGP/v17i03/46866

Maharaj, S. (2014, March 4). Streaming in schools cements inequality. The Toronto Star. Retrieved from https://www.thestar.com/opinion/commentary/2014/03/04/streaming_in_schools_cements_inequality.html

Majeed, A., Darmawan, G., \& Lynch, P. (2013). A confirmatory factor analysis of attitude toward mathematics inventory (ATMI). The Mathematics Educator, 15(1), 121-135. Retrieved from $\mathrm{http}: / /$ math.nie.edu.sg/ame/matheduc/journal/v15_1/v15_7.aspx 
Malmivuori, M. (2006). Affect and self regulation. Educational Studies in Mathematics, 63(2), 149-164. https://doi.org/10.1007/s10649-006-9022-8

Marchis, J. (2011). Factors that influence secondary school students' attitude to mathematics. Procedia - Social and Behavioral Sciences, 29, 786-793. https://doi.org/10.1016/j.sbspro.2011.11.306

Marks, H. (2000). Student engagement in instructional activity: Patterns in the elementary, middle, and high school years. American Educational Research Journal, 37(1), 153-184. https://doi.org/10.3102/00028312037001153

Marzano, R. (1998). A theory-based meta-analysis of research on instruction. Aurora CO: Mid-continent Regional Educational Laboratory.

Marzano, R., \& Kendall, J. (2007). The new taxonomy of educational objectives (2nd ed.). Thousand Oaks, CA: Corwin Press.

Mata, M., Monteiro, V., \& Peixoto, F. (2012). Attitudes towards mathematics: Effects of individual, motivational, and social support factors. Child Development Research, 2012. https://doi.org/10.1155/2012/876028

Mazer, J. (2013). Student emotional and cognitive interest as mediators of teacher communication behaviors and student engagement: An examination of direct and interaction effects. Communication Education, 62(3), 253-277. https://doi.org/10.1080/03634523.2013.777752

McLeod, D. B. (1992). Research on affect in mathematics education: A reconceptualization. In D. Grouws (Ed.), Handbook of research on mathematics teaching and learning (pp. 575-595). New York, NY: Macmillan.

McLeod, D. B., \& McLeod, S. H. (2002). Synthesis-Beliefs and mathematics education: Implications for learning, teaching, and research. In G. Leder, E. Pehkonen, \& G. Törner (Eds.), Beliefs: A hidden variable in mathematics education? (pp. 115-123). Dordrecht, The Netherlands: Kluwer Academic. https://doi.org/10.1007/0-306-47958-3_7

Meijer, J., Veenman, V., \& Van Hout-Wolters, B. (2006). Metacognitive activities in text-studying and problem-solving development of a taxonomy. Educational Research and Evaluation, 12(3), 209-237. https://doi.org/10.1080/13803610500479991

Mesa, V. (2012). Achievement goal orientations of community college mathematics students and the misalignment of instructor perceptions. Community College Review, 40(1), 46-74. https://doi.org/10.1177/0091552111435663

Middleton, J. (1995). A study of intrinsic motivation in the mathematics classroom: A personal constructs approach. Journal for Research in Mathematics Education, 26(3), 254-279. https://doi.org/10.2307/749130

Middleton, J., \& Spanias, P. (1999). Motivation for achievement in mathematics: Findings, generalizations, and criticisms of the research. Journal for Research in Mathematics Education, 30(1), 65-88. https://doi.org/10.2307/749630

Mintzberg, H. (1989). The structuring of organizations. In D. Asch \& C. Bowman (Eds). Readings in strategic management. London, UK: Palgrave. https://doi.org/10.1007/978-1-349-20317-8_23

Mohd, N., \& Mahmood, T. (2011). The effects of attitude towards problem solving in mathematics achievements. Australian Journal of Basic and Applied Sciences, 5(12), 1857-1862.

Moller, S., Stearns, E., Mickelson, R., Bottia, M., \& Banerjee, N. (2014). Is academic engagement the panacea for achievement in mathematics across racial/ethnic groups? Assessing the role of teacher culture. Social Forces, 92(4), 1513-1544. https://doi.org/10.1093/sf/sou018

Moyer, J., Robison, V., \& Cai, J. (2018). Attitudes of high-school students taught using traditional and reform mathematics curricula in middle school: A retrospective analysis. Educational Studies in Mathematics, 98(1), 115-134. https://doi.org/10.1007/s10649-018-9809-4

Mundia, L. (2011). Social desirability, non-response bias and reliability in a long self-report measure: Illustrations from the MMPI-2 administered to Brunei student teachers. Educational Psychology, 31(2), 207-224. https://doi.org/10.1080/01443410.2010.545049

Ontario Ministry of Education. (2005). The Ontario curriculum grades 9 and 10-Mathematics, revised. Toronto, ON: Queen's Printer for Ontario.

Ontario Ministry of Education. (2007). The Ontario curriculum grades 11 and 12-Mathematics, revised. 
Toronto, ON: Queen's Printer for Ontario.

Ontario Ministry of Education. (2019a, March 15). “Back-to-basics” math curriculum, renewed focus on skilled trades and cellphone bas in the classroom coming soon to Ontario (News release). Retrieved from https://news.ontario.ca/edu/en/2019/03/back-to-basics-math-curriculum-renewed-focus-on-skilled-trades-an d-cellphone-ban-in-the-classroom-co.html

Ontario Ministry of Education. (2019b, August 28). First year investment of Ontario's four-year math strategy announced (News release). Retrieved from https://news.ontario.ca/edu/en/2019/08/first-year-investment-of-ontarios-four-year-math-strategy-announce d.html

Organisation for Economic Co-operation and Development. (2016a). Program for international student assessment. Retrieved from https://data.oecd.org/pisa/mathematics-performance-pisa.htm

Organisation for Economic Co-operation and Development. (2016b). Ten questions for mathematics teachers and how PISA can help answer them. Retrieved from https://www.oecd-ilibrary.org/education/pisa_19963777

Organisation for Economic Co-operation and Development. (2019). Mathematics performance (PISA) (indicator). https://doi.org/10.1787/04711c74-en

Ouweneel, E., Schaufeli, W., \& LeBlanc, P. (2013). Believe, and you will achieve: Changes over time in self-efficacy, engagement, and performance. Applied Psychology: Health and Well-Being, 5(2), $225-247$. https://doi.org/10.1111/aphw.12008

Paige, D., Sizemore, J., \& Neace, W. (2013). Working inside the box: Exploring the relationship between student engagement and cognitive rigor. NASSP Bulletin, 97(2), $105-123$. https://doi.org/10.1177/0192636512473505

Pang, X., \& Rogers, W. T. (2013). Comparative examination of the influence of selected factors on achievement in Grade 9 Academic and Applied Mathematics courses in English-language schools in Ontario. Toronto ON: EQAO.

Patrick, H., Ryan, A., \& Kaplan, A. (2007). Early adolescents' perceptions of the classroom social environment, motivational beliefs, and engagement. Journal of Educational Psychology, 99(1), 83-98. https://doi.org/10.1037/0022-0663.99.1.83

Pepin, B., \& Roesken-Winter, B. (Eds). (2015). From beliefs to dynamic affect systems in mathematics education. New York, NY: Springer. https://doi.org/10.1007/978-3-319-06808-4

Plenty, S., \& Heubeck, B. (2013). A multidimensional analysis of changes in mathematics motivation and engagement during high school. Educational Psychology, 33(1), 14-30. https://doi.org/10.1080/01443410.2012.740199

Radford, L. (2015). Of love, frustration, and mathematics: A cultural-historical approach to emotions in mathematics teaching and learning. In B. Pepin \& B. Roesken-Winter (Eds.), From beliefs to dynamic affect systems in mathematics education: Exploring a mosaic of relationships and interactions (pp. 25-61). New York, NY: Springer. https://doi.org/10.1007/978-3-319-06808-4_2

Reeve, J. (2013). How students create motivationally supportive learning environments for themselves: The concept of agentic engagement. Journal of Educational Psychology, 105(3), 579-595. https://doi.org/10.1037/a0032690

Reeve, J., \& Jang, H. (2006). What teachers say and do to support students' autonomy during a learning activity. Journal of Educational Psychology, 98(1), 209-218. https://doi.org/10.1037/0022-0663.98.1.209

Reeve, J., \& Lee, W. (2013). Students' classroom engagement produces longitudinal changes in classroom motivation. Journal of Educational Psychology, 106(2), 527-540. https://doi.org/10.1037/a0034934

Renninger, K. A., Nieswandt, M., \& Hidi, S. (Eds.). (2015). Interest in science and mathematics learning. Washington, DC: AERA. https://doi.org/10.3102/978-0-935302-42-4

Shernoff, D., Csikszentmihalyi, M., Schneider, B., \& Shernoff, E. (2003). Student engagement in high school classrooms from the perspective of flow theory. School Psychology Quarterly, 18(2), 158-176. https://doi.org/10.1521/scpq.18.2.158.21860

Schoenfeld, A. (2015). What counts, when? Reflections on beliefs, affect, attitude, orientations, habits of mind, 
grain size, time scale, context, theory, and method. In B. Pepin \& B. Roesken-Winter (Eds.) From beliefs to dynamic affect systems in mathematics education: Exploring a mosaic of relationships and interactions (pp. 395-405). New York, NY: Springer.

Schussler, D. (2009). Beyond content: How teachers manage classrooms to facilitate intellectual engagement for disengaged students. Theory Into Practice, 48(2), 114-121. https://doi.org/10.1080/00405840902776376

Singh, K., Granville, M., \& Dika, S. (2002). Mathematics and science achievement: Effects of motivation, interest, and academic engagement. The Journal of Educational Research, 95(6), 323-332. https://doi.org/10.1080/00220670209596607

Skilling, K., Bobis, J., Martin, A., Anderson, J., \& Way, J. (2016). What secondary teachers think and do about student engagement in mathematics. Mathematics Education Research Journal, 28(4), 545-566. https://doi.org/10.1007/s13394-016-0179-x

Smart, J., \& Marshall, J. (2013). Interactions between classroom discourse, teacher questioning, and student cognitive engagement in middle school science. Journal of Science Teacher Education, 24(2), 249-267. https://doi.org/10.1007/s10972-012-9297-9

Smiley, W., \& Anderson, R. (2011). Measuring students' cognitive engagement on assessment tests: A confirmatory factor analysis of the short form of the cognitive engagement scale. Research and Practice in Assessment, 6(1), 17-28. Retrieved from https://eric.ed.gov/?id=EJ1062738

Smith, J. III, \& Star, J. (2007). Expanding the notion of impact of K-12 standards-based mathematics and reform calculus programs. Journal for Research in Mathematics Education, 38(1), 3-34. https://doi.org/10.2307/30034926

Tapia, M., \& Marsh, G. (2005). Attitudes towards mathematics inventory redux. Academic Exchange, 9(3), 272 276.

Teddlie, C., \& Tashakkori, A. (2009). Foundations of mixed methods research. Thousand Oaks, CA: Sage.

Turner, J., Midgley, C., Meyer, D., Gheen, M., Anderman, E., Kang, Y., \& Patrick, H. (2002). The classroom environment and students' reports of avoidance strategies in mathematics: A multimethod study. Journal of Educational Psychology, 94(1), 88-106. https://doi.org/10.1037/0022-0663.94.1.88

Vandecandelaere, M., Speybroeck, S., Vanlaar, G., Fraine, B., \& Van Damme, J. (2012). Learning environment and students' mathematics attitude. Studies in Educational Evaluation, 38(3-4), 107-120. https://doi.org/10.1016/j.stueduc.2012.09.001

Veenman, M., Van Hout-Wolters, B., \& Afflerbach, P. (2006). Metacognition and learning: Conceptual and methodological considerations. Metacognition Learning, $1(1), \quad 3-14$. https://doi.org/10.1007/s11409-006-6893-0

Vera., M., Le Blanc, P., Taris, T., \& Salanova, M. (2014). Patterns of engagement: The relationship between efficacy beliefs and task engagement at the individual versus collective level. Journal of Applied Psychology, 44(2), 133-144. https://doi.org/10.1111/jasp.12219

Walter, J., \& Hart, J. (2009). Understanding the complexities of student motivations in mathematics learning. The Journal of Mathematical Behavior, 28(2-3), 162-170. https://doi.org/10.1016/j.jmathb.2009.07.001

Yaratan, H., \& Kasapoğlu, L. (2012). Eighth Grade Students' Attitude, Anxiety, and Achievement Pertaining to Mathematics Lessons. Procedia - Social and Behavioral Sciences, 46, 162-171. https://doi.org/10.1016/j.sbspro.2012.05.087

Zingier, D. (2007). (Re)conceptualising student engagement: Doing education not doing time. Teaching and Teacher Education, 24(7), 1765-1776. https://doi.org/10.1016/j.tate.2007.09.004

\section{Copyrights}

Copyright for this article is retained by the author, with first publication rights granted to the journal.

This is an open-access article distributed under the terms and conditions of the Creative Commons Attribution license (http://creativecommons.org/licenses/by/4.0/). 